Portland State University

PDXScholar

Spring 7-18-2018

\title{
Effectiveness of Pollinator Enhancements in Portland Community Orchards
}

Jess Alan Tyler

Portland State University

Follow this and additional works at: https://pdxscholar.library.pdx.edu/open_access_etds

Part of the Environmental Sciences Commons

Let us know how access to this document benefits you.

Recommended Citation

Tyler, Jess Alan, "Effectiveness of Pollinator Enhancements in Portland Community Orchards" (2018). Dissertations and Theses. Paper 4463.

https://doi.org/10.15760/etd.6347

This Thesis is brought to you for free and open access. It has been accepted for inclusion in Dissertations and Theses by an authorized administrator of PDXScholar. Please contact us if we can make this document more accessible: pdxscholar@pdx.edu. 
Effectiveness of Pollinator Enhancements in Portland Community Orchards

$$
\text { by }
$$

Jess Alan Tyler

A thesis submitted in partial fulfillment of the requirements for the degree of

\author{
Master of Science \\ in \\ Environmental Science and Management
}

Thesis Committee:

Marion Dresner, Chair

Susan Masta

Jeffrey Gerwing

Portland State University

2018 


\begin{abstract}
In urban areas, residential and community gardens are potential floral resources for pollinators. Pollinator "friendly" gardens are a popular way to support this ecosystem service, but the pollinator plant list recommendations lack empirical evidence to show which plants are most attractive to potential pollinators. This project used a community science survey based on a morpho-species protocol to monitor five community orchards in Portland, Oregon during six months of the growing season in 2017. Overall, orchards with higher floral species richness supported higher richness and abundance of pollinators, but the pollinator communities were not significantly different among the orchard sites. Orchard fruit-set had a variable correlation with pollinator richness and abundance. At the landscape level, the number of miles of street within 500m showed a strong negative correlation with the overall pollinator community richness. Bumble bee abundance showed a strong negative correlation with the percentage of single family residential zoning, and NDVI at 2000 meters. Our community science approach promoted volunteer awareness of pollinator diversity in Portland, but did not increase volunteer intention to conserve pollinators. This research helped build evidence of the dynamics of urban pollinators and the role that community science can play in pollinator biodiversity monitoring.
\end{abstract}




\section{Acknowledgments}

This project had the help of many people. The biggest thanks goes to the volunteers who donated their time to improve our understanding of pollinators in our city. Thanks for all your effort and time: Brian Wagner, Denny Wilson, Dera Look, Jamie Stamberger, Jen Baye, Lauren Yap, Nathan Riggsby, Michelle Hannah, Raquel Ruiz, Sachi Arakawa, Shareh Asadi, Stephen Haber, Szilvia Frazier, Tiiu Magi, and Trish Stormont.

Thanks to the Portland Fruit Tree Project for supporting this project, allowing me access to the orchards, and the usage of facilities and office supplies.

The East Multnomah Soil and Water Conservation District provided a \$1,500 SPACE grant for this project, which supported our presenters at the trainings, lunch at the trainings for volunteers, and project supplies. Thanks for making this research possible.

I acknowledge the Xerces Society for their citizen science monitoring protocol, which provided an excellent framework for this project.

Finally, thanks also to Dr. Marion Dresner for advising me on this project, and to Dr. Susan Masta and Celeste Ets-Hokin for helping with my trainings. 


\section{Table of Contents}

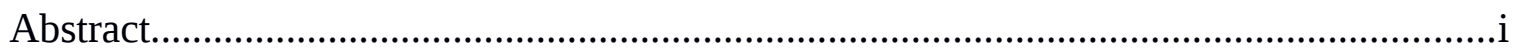

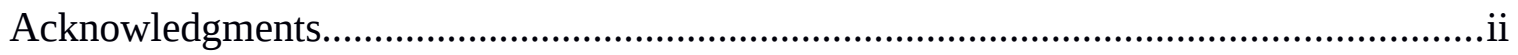

Table of Contents.....................................................................................................ii

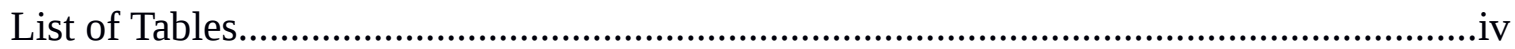

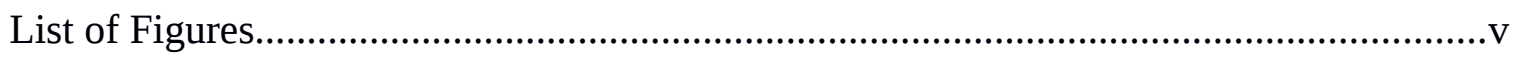

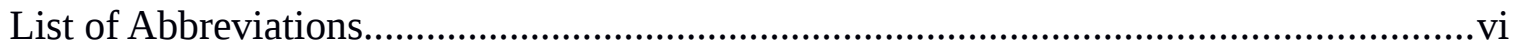

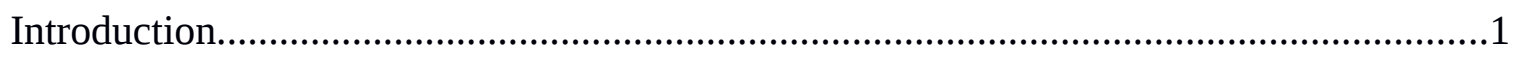

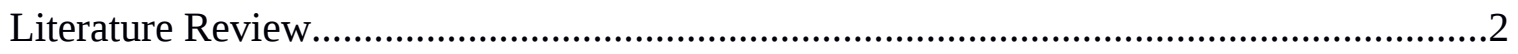

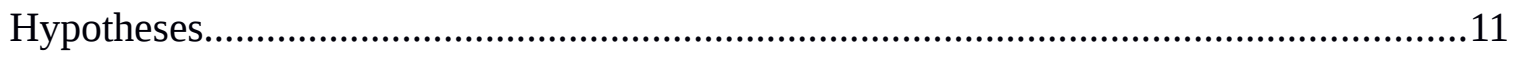

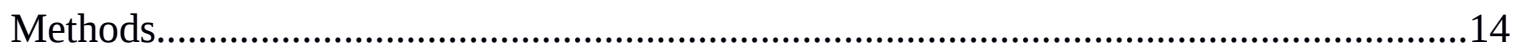

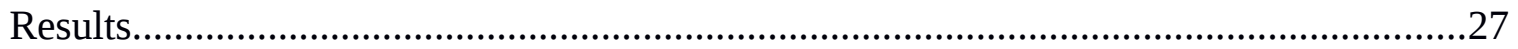

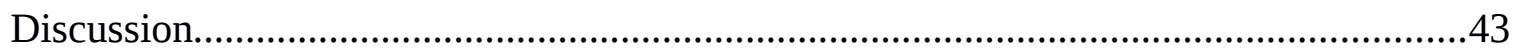

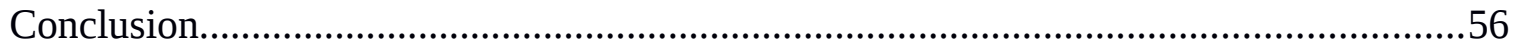

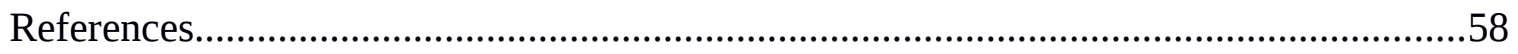

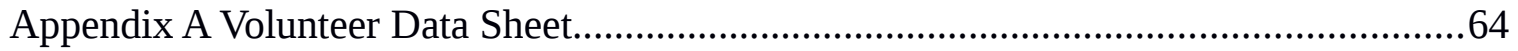

Appendix B Volunteer Surveys.........................................................................66

Appendix C Pollinators Count! Data.................................................................... 70 


\section{List of Tables}

Table 1: Questions for volunteer focus group.

Table 2. Orchard pollinator community averages for the whole monitoring period.

Table 3. Average distance to orchard group centroid.

Table 4. Anosim results comparing orchards for community difference by season.

Table 5. Orchard transect diversity.

Table 6. Intentionally planted orchard flowering plants recorded on transects.

Table 7. Orchard vegetation survey summary statistics for plant species richness.

Table 8. Spearman Rank Correlation between pollinator community and vegetation surveys.

Table 9. GIS Analysis of orchards.

Table 10. Spearman rank correlations between pollinator community and urban landscape characteristics. Standard error for correlations of sample size 4 is 0.365 .

Table 11. Orchard canopy volume and fruit set.

Table 12. Pollinator community averages in the spring season.

Table 13. Spearman rank correlation between fruit set and number of bee groups and abundances and orchard fruit production. Standard error $=0.365$.

Table 14. Spearman rank correlation between fruit set and tree size. 


\section{List of Figures}

Figure 1. Aerial image of Portland, Oregon with PFTP orchard locations.

Figure 2. Tree canopy volume calculation. $\mathrm{H}_{\text {tree }}$ is the height of the tallest branch. $\mathrm{H}_{\text {lowest }}$ branch is the distance from the ground to the lowest branch. $\mathrm{W}_{\mathrm{N}-\mathrm{S}}$ is the furthest distance of branches measured in a north-south direction. $\mathrm{W}_{\mathrm{E}-\mathrm{w}}$ is the furthest distance of branches measured in an east -west direction.

Figure 3. Pollinator morpho-species richness and abundance across the growing season.

Figure 4. Pollinator community change over time: (A) Early Spring, (B) Late Spring

Early Summer, (C) Mid Summer, and (D) Late Summer Early Fall.

Figure 5. Eigenanalysis of orchard pollinator communities. 


\section{List of Abbreviations}

\begin{tabular}{|c|c|}
\hline HB & Honey Bee \\
\hline $\mathrm{BB}$ & Bumble Bee \\
\hline CLB & Chap Leg Bee \\
\hline MDB & Medium Dark Bee \\
\hline MGB & Metallic Green Bee \\
\hline SSB & Striped Sweat Bee \\
\hline TDB & Tiny Dark Bee \\
\hline SHBB & Striped Hairy Belly Bee \\
\hline MHBB & Metallic Hairy Belly Bee \\
\hline CB & Cuckoo Bee \\
\hline FOD & Fruits of Diversity Orchard \\
\hline PR & Parkrose Orchard \\
\hline GT & Green Thumb Orchard \\
\hline ORCA & Oregon Recreation and Conservation Area \\
\hline SFR & Single Family Residential Zoning Area \\
\hline NDVI & Normalized Difference Vegetation Index \\
\hline
\end{tabular}




\section{Introduction}

Cities support a diversity of pollinator species that is highly dependent upon human landscaping choices. There is a need to understand how the arrangement and composition of plant species in cities influences insect pollinator populations. Many individuals and organizations rely on lists of "pollinator friendly" plants to inform their landscaping choices, but these lists lack concrete evidence as to the attractiveness of individual plant species for bees and other pollinators. This lack of evidence can lead to floral plantings in cities with sub-optimal benefits to pollinators.

This study of pollinator enhancements in Portland, Oregon community orchards is intended to provide information on landscape and garden influences on urban pollinators. The community orchard study sites are managed by a volunteer-run non-profit group called the Portland Fruit Tree Project (PFTP) who's mission is “...to increase equitable access to healthful food and strengthen communities by empowering neighbors to share in the harvest and care of city-grown produce." ("Portland Fruit Tree Project - About" n.d.). Over several years, PFTP has added many under-story plants to the orchard area that are intended to provide benefits such as nitrogen fixation, speed breakdown of mulch, and provide nectar resources for local pollinators. PFTP volunteers helped to collect the data for this project.

My goals for this study were to:

- Survey PFTP's five orchard sites for pollinators from March to September 2017

- Identify which bees visit orchard trees and specific orchard plants

- Produce a report for PFTP on the effectiveness of their under-story plantings 


\section{Literature Review: Bees in Urban Landscapes}

Pollinators are finding new homes in cities. In 2011, scientists identified four new species of bees within the city of New York and in the surrounding counties including Lasioglossum gotham, a small sweat bee, named for the city where it was discovered (Gibbs 2011, Olsen 2011). According to Hall et al. (2017), many cities may actually have conservation value for pollinators despite a widespread impression that cities are biological deserts for nearly all wildlife (Hall et al. 2017). Systematic study of urban ecosystems is revealing new trends and relationships between humans and wildlife, and through this research we can better know our place in the biological community.

Cities support a diversity of life that is highly dependent upon the influence of human landscaping choices. Urbanized areas now account for 1-6\% of the world's terrestrial landscape, but are rapidly expanding (Meyer and Turner 1992). Urban landscapes are characterized by having high amounts of human disturbance that fragment habitat in a wide area around the city. This fragmentation disrupts ecological systems along a gradient from rural to urban and typically increases the amount of impervious surface and decreases the amount of open land as you move towards the center of a city (Luck and Wu 2002). Increasingly, ecologists are studying population dynamics in urban areas across a wide range of species. Findings have ranged from sharp declines in abundance and richness for some plants and animals, to modest gains in richness or abundance for certain plant species and synanthropic bird species (McKinney 2008). The general pattern is that urban areas decrease abundance and richness for many species, but there is evidence that this is not a uniformly negative association (Frankie and Ehler 1978). 
Pollination by animals is a vital ecosystem service, but many species of pollinators are declining worldwide (Potts et al. 2010), and scientist and gardeners alike are looking for ways to help sustain pollinator populations. Pollinator decline has many causes including: habitat fragmentation, air pollution, poisonous chemicals, and lack of food and habitat (Goddard et al. 2010, Brown et al. 2016). Honey bees in Europe and North America have been hit particularly hard which has been detrimental to agriculture and the most direct human need for insect pollinators (Ghazoul 2005). The economic worth of pollination service in the United States is valued at $\$ 29$ billion (Calderone 2012), and in the wake of massive die offs of honey bee colonies, farmers and scientists are finding ways to diagnose the pollinator problems and promote pollinators wherever they live.

Pollination also occurs even in traditionally understudied urban ecosystems. It is important to understand how bees are influenced by the urban environment so we can ensure their continued survival - for the pollination they provide to backyard gardens and for continued plant diversity. Many, but not all, studies of urban bees have shown negative associations with urbanization (Cane et al. 2006; Matteson et al. 2008; Zanette et al. 2005). Habitat quality and floral resource availability are key components to sustaining bee populations, and some studies have shown that urban areas support more bee species, especially for cavity nesting bees (Hernandez et al. 2009) likely because of the enhanced floral abundance of residential yards compared to rural areas. Matheson (2008) demonstrated that richness of cavity nesting bees was greater in the Manhattan area of New York City compared to outlying suburbs. Urban parks and gardens in 
Manhattan provided the resources necessary for bees to survive despite being highly urban.

Urban areas have their own challenges for pollinators, but with the rising popularity of urban community gardens and "pollinator gardens", urban pollinators have shown surprising resilience (Hall et al. 2017). Urban areas tend to have fewer insect pollinator species and they represent only a narrow range of species that can tolerate the urban environment (Hernandez et al. 2009). Many surveys have been done at community gardens where floral resources are plentiful for these insects. A pollinator survey in New York City found 54 species of pollinators in urban gardens (Matteson et al. 2008), and a survey of community gardens in seven California cities found between 41 and 82 species (19-28 genera) present (Frankie et al. 2009). Community gardens are great potential habitats for insect pollinators with nectar resources and open area for nesting. However, bee diversity is highly variable in cities and depends heavily on the available food, water, and habitat (Goddard et al., 2010).

\section{Landscape scale studies}

Floral resources and nesting habitat distribution are of primary importance for urban bees. Where bees forage and nest can be understood in relation to landscape metrics such as land use type, patch size, number of patches, edge density, and other metrics used to describe natural landscapes (Luck and Wu 2002). Patch size for bee habitat in an urban landscape area is difficult to define due to their reliance on multiple habitat patches for foraging and nesting (Hernandez et al. 2009). Additionally, it is difficult to locate a bee's nesting site, so this information is rarely considered for 
population studies. Biologists use land use type, as well as distance to potential habitat areas within the study area, as a shortcut or proxy for determining exactly where bees nest and how far they travel to forage. Land use types often include: urban, suburban, rural, commercial, residential, agricultural, vacant land, park land, and others. This landscape level data describes urban habitat suitability and matrix permeability as a function of landscape structure.

Many studies correlate distance to habitat features within the urban landscape to bee abundance and species richness, and collectively have found similar trends for urban bee populations. Urban areas tend to support cavity nesting bees as well as bees with larger body size, and who tend to be generalists in their feeding strategy (Hernandez et al. 2009). Several studies found no difference in richness between urban and rural areas, but different assemblages of bees in each site (Zanette et al. 2004, Antonini et al. 2012, Hostetler and McIntyre 2001). Other studies have found negative associations with urbanization (Threlfall et al. 2015) It is difficult to generalize about all bees across all cities due to the feeding and nesting habits of this diverse insect group and the differences between cities.

Landscape characteristics explain some but not all of the differences in bee assemblages even when richness and abundance do not significantly differ. Antonini et al. (2012) found no difference in richness in subtropical stingless bees in forest fragments regardless of size in an urban area in southeastern Brazil. In another study, Hostetler and McIntyre (2001) found a significantly higher bee richness in desert parks than in residential yards throughout the Phoenix metro area. They found a significant negative 
relationship between built structures and bee communities, but no relationship between richness or abundance and distance to desert fragments. This suggests the urban landscape is only permeable to certain species, or that the desert fragments do not function as sources for the bee population, which would imply the farther away you got from them the fewer bees one would find. Habitat character with native (xeric adapted) plants and density of human built structures seemed to best explain variation in bee communities (Hostetler and McIntyre 2001).

Geographic Information Systems (GIS) technology is a powerful tool for pollinator research and some studies use GIS to identify buffer zones around study sites to correlate landscape metrics to population variation. Landscape elements are then identified within each buffer area, including different land uses, presence/number of forest patches, area of forest or wetland, open area, percent impervious surface, etc. These studies use a variety of survey methods including genetic studies (Jha and Kremen 2013; Davis et al. 2010; Lopez-Uribe et al. 2015). To analyze the landscape variables, circles of a range of radii (e.g. 500m, 1000m, 1500m, 2000m) were drawn around each sample site to create buffer areas. Buffer studies like this have found significant landscape effects for urban bee populations at ranges as low as $250 \mathrm{~m}$ and as large as $2000 \mathrm{~m}$.

Surveying multiple kinds of bees can also effect the overall outcome, because landscape characteristics may influence bee species individually. For example, Wojick and McBride (2011) found that smaller-bodied bees of the family Halictidae were more affected by landscape character than large-bodied bumble bees. Large-bodied bumble 
bees are able to travel further - up to two kilometers in some cases - in search of forage (Hatfield and Lebuhn 2007), while smaller bodied bees are limited by plants nearby because they do not travel as far to forage (Wojick and McBride 2011).

City landscapes are very novel with many introduced species coexisting with remnant species in an environment with altered chemistry and climate due to the urban heat island effect. Importantly, for urban pollinators, cities change bloom times, lengthen growing seasons, and otherwise alter plant physiology with increased access to nutrients. Cities have been shown to have unique plant communities with highly variable amounts of floral resources compared to nearby rural area (Leong et al. 2016). Phenotypic plasticity, therefore, becomes important for urban species, and there is evidence to support this kind of adaptation (Leong et al. 2016). Specialist species who can adapt to new plants that are similar enough to their preferred plant are better able to survive, and generalists have an even wider range of plants on which to forage. In this way, cities act as species filters which promote adaptive, predominately cavity nesting and generalist bee species (Hernandez 2009).

\section{Socio-environmental aspects of urban bees}

Urban areas have unique effects for all pollinators. There is evidence that in parts of cities with intermediate levels of urbanization and abundant floral resources, certain bees can thrive (Hernandez et al. 2009). In many cases, the local characteristics of a neighborhood, such as floral abundance, are more important than landscape variables such as distance to city center or percent impervious surface (Wojcik and McBride 2012, Shwartz et al. 2013, Foster et al. 2017). This implies that while cities can have great 
variability in species richness over an area, the habitat can also be improved with changes in land use practices.

Bees and other insects function at relatively small spatial and temporal scales based on their nesting habitat, forage needs, and life cycles (Hall et al 2017), in contrast to birds and mammals who need larger forage areas, larger nesting sites, and who live longer. Changes at the neighborhood scale are therefore sufficient to have biologic value to these pollinators. Urban areas support insect pollinators to highly variable degrees as a result of natural variation in individual choices concerning landscape practices that have consequences for pollinators and for wildlife more broadly. Importantly, the small-scale habitat variable of residential yard composition has been shown to also be important in understanding how bees adapt to the urban environment. Pardee and Philpott (2014) surveyed bees in northwestern Ohio and found yards with native plants had higher bee abundance in all cases, but similar richness was reported in yards without native plants.

At the yard and neighborhood scale, the amount, kind, and placement of plants plays a key role in pollinator success in cities. Consequently, backyard habitat certification and "holistic" management often focus on "native” plants. It is believed that wildlife broadly has a more natural rapport with plants from their local bioregion, and therefore is better able to utilize those resources. This assumption has been challenged by researchers, and many sources suggest that there is no clear preference for native plants by pollinating insects or birds (Burghardt et al. 2009, Hanley et al. 2014, Dresner and Moldenke 2017). Insects and birds both show similar species richness and behaviors in habitats of similar plant species richness with or without predominantly native species. 
Comparatively little research has been done to quantify the "attractiveness" of certain plants for pollinators in urban settings. Generally, individuals use plants that are easily available to them and/or are on authoritative lists of "pollinator friendly" or "native" plants. These lists come from many different organizations, but overall lack empirical evidence to support the preference for some plants over others. Garbuzov and Ratnieks (2014) systematically quantified bee “attractiveness” for common landscape plants in the United Kingdom. They are one of the only researchers to have done this work and found a wide range of attractiveness and up to a 100-fold difference in attractiveness between plant species (Garbuzov and Ratnieks 2014). This result may not be surprising, but more study is needed to understand attractiveness for plants in different regions.

\section{Community Science}

Since the 1700s, everyday people have been giving their time and expertise to help answer scientific questions. Non-experts participating in science is now called community science or citizen science. One of the most famous and enduring community science projects is the Christmas Day Bird Count run by the Audubon Society in the USA every year since 1900 . Volunteers have been counting birds and monitoring other sorts of wildlife in different areas for at least the past century. According to Theobald et al. (2014) community science projects engage 1.3 million people annually in hundreds of ongoing projects.

Currently, community members are involved in all kinds of projects, especially in the fields of environmental science and biology (Silvertown 2009). Amateur naturalists 
contribute to a growing number of projects to monitor populations as well as provide data to answer specific hypotheses. The accessibility of data and information has made training and engaging volunteers much easier. These projects benefit both the scientist and the people who contribute.

Community science has been gaining momentum and also validation in the scientific community. According to Silvertown (2009), there are several challenges faced by community science projects including: data validation, collection standardization, using explicit assumptions, and how to reward participants for their work. When these challenges are addressed, data gathered by volunteers can be just as good as that gathered by professionals (Droge 2007). Volunteer-run projects have the added benefits of greater investment by the participants who often can contribute longer and do not require the financial resources of hiring technicians. In the context of pollinator research, Kremen et al. (2010) showed that citizen data had a significant positive correlation with that of trained scientists. Citizen data does not have the same species resolution, so it lacks the ability to detect abundance changes for specific pollinator species, but it can show community change (Kremen et al. 2010).

\section{Pollinators Count!}

The official name for this community science project is Pollinators Count! The inspiration for this project came out of a desire to understand the benefits of "holistic" orchard management practices and as a way to educate and engage volunteers around the topic of pollinators. Fruit production and education are the main goals of the Portland Fruit Tree Project, and this project helps meet both of those goals by engaging volunteers 
in research to understand how to improve fruit production by creating beneficial pollinator habitat.

\section{Hypotheses}

The Portland Fruit Tree Project has been increasing the floral richness of their community orchards over the past five years partly with the intention of creating better pollinator habitat among other goals. The pollinator habitat enhancements have been done in non-uniform ways in different orchards according to different management styles. Plant selections in the highly managed orchards reflect values of PFTP, as well as factors such as funding and available volunteer labor. Pollinator observations are also influenced on any given day by environmental factors such as weather, flowering patterns, and landscape character. Despite these factors, an important goal of this project is to attempt to explain differences in pollinator community as a function of floral richness, especially richness of “pollinator friendly” plants (hypothesis 1).

The type and abundance of vegetation in the surrounding area has also been shown to have a measurable effect on the pollinator community. The vegetation in the urban landscape represents potential habitat and floral resources for pollinators. I hypothesize that the influence of landscape variables will effect pollinator diversity, whereby closer resources (within 500m) will correlate with an increased number of morpho-species per observation, primarily because of the increase in smaller-bodied bees similar to the results from Wojick and McBride (2012). Smaller-bodied bees are not present in only one morpho-species and will therefore increase the overall morphospecies richness per observation. Larger bees such as bumble bees will benefit from 
better potential habitat across a broader area, and I hypothesize that the effect will be visible in a 2000m buffer area because that has been shown to be their approximate maximum forage range (Hatfield and LeBuhn 2007) (hypothesis 2).

Producing fruit is one of the primary goals of an orchard and enhancements to floral richness, especially during the fruit tree bloom period, is believed to increase the number of pollinators in an orchard area. Promoting pollinators in the orchards is then expected to also boost pollination for the fruit trees and increase orchard fruit production (hypothesis 3).

Finally, engaging community members in this monitoring project is expected to have multiple benefits. I hypothesize that volunteers will specifically have a greater intention to promote pollinator habitat on their own as a result of participating in Pollinators Count! (hypothesis 4).

Hypotheses

1. Orchards with a greater species richness of "pollinator-friendly" flowering plants will host a greater pollinator richness.

2. Orchards with more potential nearby habitat (within 500 meters) will have higher total pollinator richness and will have higher bumble bee abundance with more potential habitat farther (within 2000 meters).

3. Orchards with a larger abundance of any pollinators in the orchards during the fruit tree bloom period will produce more fruit-lets on average for each fruit tree group: apple, pear, and plum.

4. Volunteer participation in this project will increase participant intention to 
promote pollinator habitat in their residential yard space. 


\section{Methods}

\section{Site description}

The Portland Fruit Tree Project orchard sites are located within the city limits of Portland, Oregon (Figure 2). Portland is a mid-sized American city situated at the confluence of the Willamette and Columbia Rivers with a population of nearly 600,000 people (American Fact Finder). It was founded in 1851 and now covers an area of 344 $\mathrm{km}^{2}$ (U.S. Census Bureau). The climate in Portland is Mediterranean with cool, wet winters and warm, dry summers, and falls within the USDA hardiness zone $8 \mathrm{a}$ and $8 \mathrm{~b}$ (USDA). The average annual rainfall is $1088 \mathrm{~mm}$ and the average temperature in August is $20.5^{\circ} \mathrm{C}$ and annually $12.5^{\circ} \mathrm{C}$ (NOAA).

The orchard study sites are maintained and improved by volunteers, and are located in diverse surroundings such as next to or within city parks, within a dense residential area, or in the back lot of a church next to a community garden. Each orchard varies in age from approximately 30 years (Gabriel Orchard) to only three years (Parkrose Orchard). They also vary in structure from a standard-row orchard (Gabriel and Parkrose) to a less structured system (Sabin) or a hybrid of systematic rows and free-form spacing (Fruits of Diversity). The orchards have a variety of fruit trees including: apples, pears, plums, cherries, persimmons, hazelnuts, nectarines, quince, and fig. There are also other edible plants including several kinds of berries and culinary herbs. All of the orchards except Gabriel have been augmented with different amounts and arrangements of flowering plants to add aesthetic and environmental benefits to the sites. 


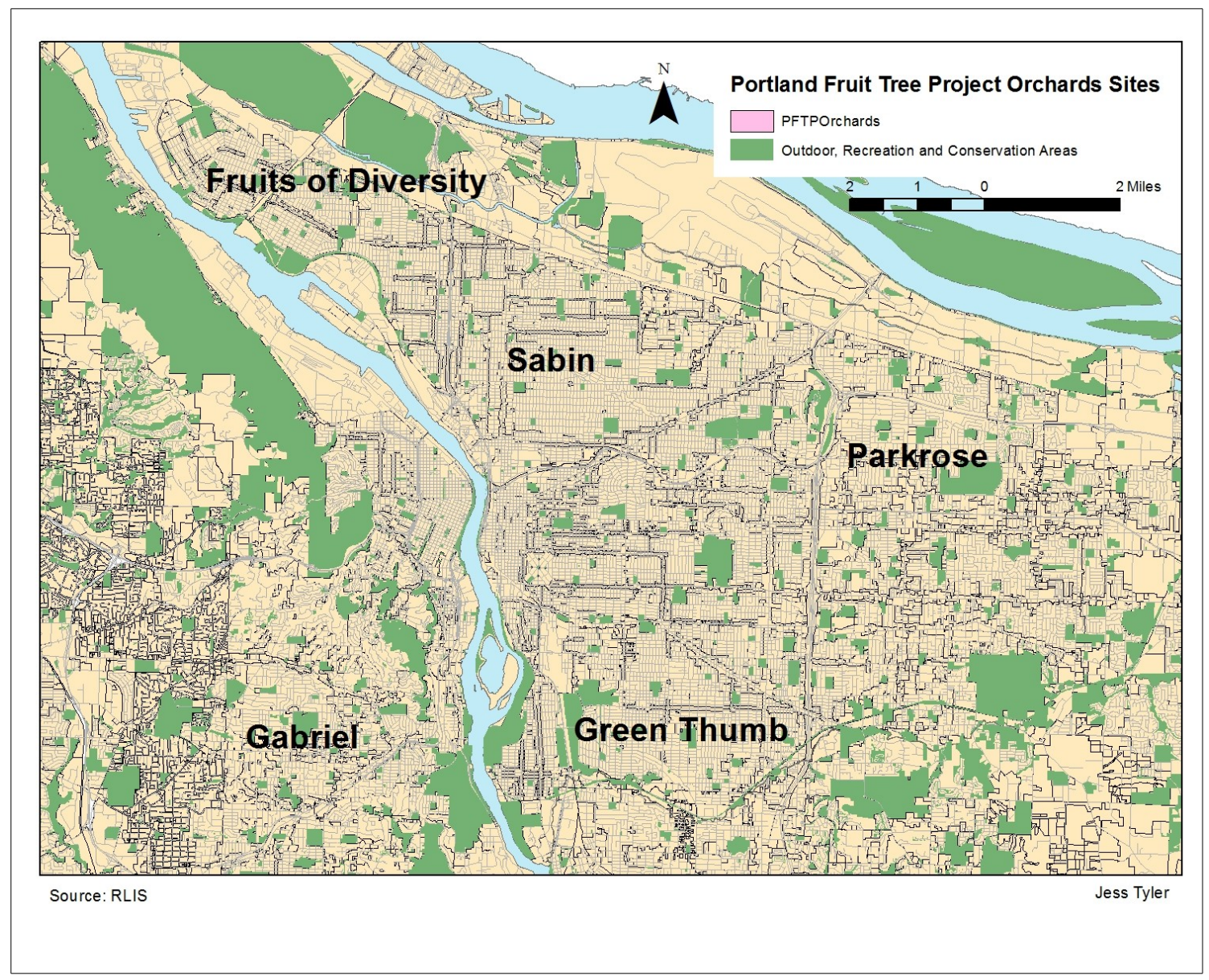

Figure 1. Aerial image of Portland, Oregon with PFTP orchard locations.

\section{Community Science Pollinator Observations}

In order to answer the question of how pollinator enhancements are affecting orchard pollinator diversity, pollinator taxa were collected at each community orchard once per week from March-September 2017. Volunteer community scientists played a vital role in collecting data for this project.

The monitoring protocol for this project is based on the community science monitoring protocol for the maritime northwest created by the Xerces Society (Minnerath 
et al. 2016). Pollinators were monitored along a transect at regular intervals using only live "on-the-wing” observations without any collection. Pollinators were grouped into 10 "morpho-species" based on characteristics such as size and color, which are easy for volunteers to learn and readily identify. The 10 morpho-species were: honey bee (Apis mellifera), bumble bee (Bombus spp.), chap leg bee, striped sweat bee, medium dark bee, metallic green bee, metallic hairy belly bee, striped hairy belly bee, tiny dark bee, and cuckoo bee. Non-bee pollinators were also recorded and grouped as broadly: "fly”, "ant”, "beetle”, "true bug”, "wasp”, “spider”, and "bird”.

This morpho-species protocol was tested by Kremen et al. (2010) who found this method strongly correlated with data from professional entomologists and is very useful in monitoring community change over time. The approachability and positive response from the scientific community were reasons for adopting this protocol over others.

Each orchard was monitored for pollinators using a transect method. The transect for each orchard was selected to run roughly through the middle and along the long axis of the orchard. Transects were selected to be along a path through the orchard or to cut a straight line through it, whichever was more convenient for volunteers to traverse. Transects were selected to coincide with a large amount of established pollinator enhancement plants for easy access for observations. The transect length was designated to run through the full length of the orchard with values ranging from $60 \mathrm{~m}$ to $100 \mathrm{~m}$ depending on the arrangement of the orchard. Transects were allowed to be curvilinear to follow an established path as long as they didn't make corners of 90 degrees or sharper. Volunteers were instructed to walk the orchard transect for a period of 10 minutes 
during each monitoring day. They were to observe pollinators on flowers only within a distance of two meters on either side of the transect and record their observation on a provided data sheet (appendix A). Observation sheets included time/date, weather information (temperature, wind, and cloudiness), along with information on the morphospecies observed, number observed, and plant observed. Volunteers were provided with a "bug vacuum” with which to collect pollinators "on the wing”. They were also encouraged, but not required, to photograph each different kind of pollinator they observed.

Photographs of pollinators were checked for accuracy and error rate was established as the number of incorrect classifications/total number of photographs.

\section{Volunteer Surveys}

Volunteers for the Pollinators Count! project were surveyed during a mid-project check-in and in an end-of-project survey (appendix B). The surveys were designed to assess volunteer's pre- and post-project knowledge about pollinators and community science, and assess their experience and motivation. Basic demographic information was also collected. No statistical analysis was conducted on the survey responses.

The mid-season survey asked five questions pertaining to participant motivations, had a section where volunteers could describe their sources of information on pollinators, and had nine questions to assess their previous knowledge and satisfaction with the classroom trainings based on a Likert scale (1-10).

The post-season survey asked nine questions about how volunteers felt about the project (Likert scale 1-10), provided a place to submit feedback for improvements, and 
collected information on income, age, ethnicity, and level of education.

\section{Fruit Production}

The amount of fruit produced at each orchard site was quantified using a systematic sampling of the number of fruit on each tree. Each tree was sampled in each of the five orchards in July of 2017. The number of successful fruit produced by each tree at mid-season was taken to be an approximate indicator of both the rate of successful pollination and the number of harvest-able fruit. The size and weight of the end-of-season fruit harvest were not recorded.

Fruit production at mid-season was surveyed by totaling the number of fruit on three "representative” branches of each tree. Production was averaged across trees that fell into the three categories of apple, pear, and plum regardless of age or variety of the tree. Three "representative" branches were selected according to the following criteria: those within the reach of the recorder from standing, branches between $1 \mathrm{~cm}$ and $3 \mathrm{~cm}$ in width measured at the point where it met another branch, and branches that were as far apart as possible from each other. Once a branch was selected, the number of fruit was counted regardless of size or condition. The width of the branch was also measured using a DBH tape at the point where it branched. Branch width was measured to the nearest millimeter.

The average fruit per branch was averaged for each tree and for each tree of the broad groups apple, pear, and plum within each orchard. The number of fruit per branch per unit of branch with was also averaged for each tree and across the whole orchard. 


\section{Tree Canopy Volume}

Tree canopy volume was measured for each orchard tree in the three broad groups of apple, pear, and plum to provide a proxy for tree biomass. Canopy volume measurements were taken over the month of July 2017. Canopy volume was calculated based on the formula:

$$
\text { Canopy Volume }=\left(H_{\text {tree }}-H_{\text {lowest branch }}\right) * W_{\mathrm{N}-\mathrm{S}} * W_{\mathrm{E}-\mathrm{W}}
$$

Figure 2. Tree canopy volume calculation. $\mathrm{H}_{\text {tree }}$ is the height of the tallest branch. $\mathrm{H}_{\text {lowest }}$ branch is the distance from the ground to the lowest branch. $\mathrm{W}_{\mathrm{N}-\mathrm{S}}$ is the furthest distance of branches measured in a north-south direction. $\mathrm{W}_{\mathrm{E}-\mathrm{W}}$ is the furthest distance of branches measured in an east -west direction.

Height and width measurements were taken as the longest possible value out to the end of any leaf/branch regardless of the general shape of the canopy. Values were rounded to the nearest $0.1 \mathrm{~m}$.

Tree stem diameter was measured at a height of $0.5 \mathrm{~m}$ and measured to the nearest millimeter.

\section{Transect inventory}

Each orchard had been planted with pollinator enhancement plants within the past five years with a variety of type and number of plants used. A full inventory was necessary to determine the plant community along each orchard transect. Once the observation transect had been established, I conducted a full inventory of the intentionally planted species with two meters from the centerline of the transect. This 
plant inventory was conducted during the month of July for each orchard. The plants that were included in the inventory had to be within the two meter buffer along the transect and included any flowering plant but not including common weeds or grasses. Plants were identified to the genus level or species when possible. Each plant genus (or species) was then classified as a pollinator-friendly plant based on its inclusion in the USDA's “Plants for Pollinators in Oregon” publication (Pendergrass et al. 2008).

\section{Orchard Plant Survey}

The overall flowering plant richness of each orchard was also determined with a vegetation survey. The objective of this vegetation survey was to determine the background number of flowering plant species which contribute floral resources, in addition to intentional pollinator enhancement plants. The survey was performed using a stratified random sampling method. First, each orchard area was calculated as the shape of a rectangle. The orchard area would be divided up into regular transects and sampled at regular intervals to accommodate a chosen number of 30 samples per site. The number of plots per transect was determined using the formula $\sqrt{ }(30 \mathrm{x}$ Width/Length) and rounded down to the nearest whole number. This number was then used to determine the number of transects 30/(\# of plots per transect). Each transect would be at most Length/(\# of transects) apart from each other and the spacing of plots would be at most Width/(\# of plots per transect) apart rounded down to the nearest whole number. The location of the first transect was a whole number of meters between zero and Length/(\# of transects rounded down). A number was chosen using a random number table. The location of the first plot on the transect was chosen from a random number table between 0 and Width/(\# 
of plots rounded down). The second plot along the transect was placed width/(\# of plots) away from the first plot. Plots were $1 \mathrm{~m}$ x $1 \mathrm{~m}$ quadrants made of plastic pipe with the lower left corner placed at the randomly chosen coordinate. Within each plot, only the number of flowering plants taxa was recorded (excluding grasses). Plants were identified to genus level or species when possible. Photographs were taken for identification of unknown plants.

The total floral richness of each orchard ( $\gamma$ diversity) was determined as the total number of flowering (non-grass) species. The number of species within each plot ( $\alpha$ diversity) was compared across all plots in an orchard to get mean and standard deviation of $\alpha$ diversity. Finally, $\beta$ diversity or species turnover was calculated $\gamma$ diversity/ mean $\alpha$ diversity.

\section{Landscape analysis}

Geographic Information Systems (GIS) techniques were used to quantify landscape characteristics of the area surrounding each community orchard. The objective of the GIS analysis was to describe the degree of urbanization surrounding the community orchards in order to assess how much potential habitat and floral resources are available to pollinators. Based on previous studies, the urban landscape was quantified using GIS in four metrics including: ORCA (Oregon Recreation and Conservation Areas) measured in square miles, street length measured in miles, percent of land zoned as single family residential (SFR), and normalized difference vegetation index (NDVI). Each metric was calculated using ArcMAP for each orchard site at distances of 500m and 2000m. 
All of the data for this analysis was obtained from Oregon Metro's RLIS database www.rlisdiscovery.oregonmetro.gov.

\section{Focus Groups}

Focus groups were conducted in December 2017 and January 2018 as part of an effort to understand volunteer intentions and motivations. Five project volunteers attended. The focus groups consisted of informal meetings between volunteers and myself in a neutral setting for approximately 45 minutes. The intention of these focus groups was to provide qualitative information on the outcomes of the project for the volunteers. These focus groups were set up as informal interviews where I asked my volunteers to reflect on the findings and operation of the project, their views on the importance of pollinators, and their input on the value of this work in the context of the PFTP. The volunteers were asked a structured set of questions in order to get their opinions, and the conversations were recorded, but no coding analysis was conducted on their responses. The questions used during the sessions appear in Table 1:

Table 1: Questions for volunteer focus group

1. After looking at the report, what do you think about the findings?

2. How important is it to have pollinators, especially in a city?

3. Did the project change your attitudes about pollinators?

4. Do you plan to do any pollinator related activities in 2018 ?

5. Assuming you continued with this project continued for the next few years what would you want to get out out of it?

6. How could Pollinators Count! be run more smoothly? Were the schedule sheets 
helpful?

7. What is your current interest or involvement with PFTP?

8. Why is PFTP's work valuable to you?

9. Is Pollinator's Count! a way to be involved in PFTP that suits your interest better than other opportunities?

\section{Analysis}

\section{Data Clean-up and Imputing Values}

Due to the nature of volunteer data gathering, there were gaps in the observation and variation in which orchards were visited most often. This project did not reach the goal of having data for each week of the growing season, but with minimal exception there was enough data for a pollinator record for every other week (twice a month). To create a dataset of equal sampling effort across orchards, only a subset of the total number of observations was included in subsequent analysis. Each orchard's observation pool was used to select two observations per month for each orchard for a total of 12 observations per orchard. In the event that there were multiple observation days per two week period, the observation which was taken closest to $12 \mathrm{pm}$ was used as the representative observation. This rule was used because the data from this project indicated that the hour between 12pm and 1pm showed the greatest abundance of bees when averaged across the season. Pollinator observations were separated into seasons according to the following calendar: Early Spring (April), Late Spring Early/Summer (May and June), Midsummer (July), and Late Summer/Early Fall (August and September). 
Two imputing techniques were used for when there was no observation for an orchard during a two-week period. For overall analysis to develop average number of morpho-species groups and average abundance values, a null value was imputed for each missing observation (three imputed values total). This is a conservative approach established so as not to introduce bias into the data set, and also because it reflects a very real probability that no pollinators would be observed. A different imputing method was used to calculate homogeneity of variance among the orchard sites, as well as the analysis of similarity calculations. The seasonal average value was imputed for missing values in this case, in order to calculate meaningful Bray-Curtis dissimilarity among all data points. The average value was chosen because null values are not compatible when using Bray-Curtis dissimilarity and because it is a straight-forward method to give a value that is similar to other values within the season.

\section{Multivariate Homogeneity of Variance}

Pollinator community similarity was assessed by first quantifying variance within orchard groups. Each orchard community data point consisted of 12 variables including the 10 morpho-species groups and a variable for the number of flies observed and number of “other pollinators” observed. Distance between data points was calculated using BrayCurtis dissimilarity.

A multivariate homogeneity of variance test is the multivariate extension of Levene's test for equal variance. Using the vegan package in R (Oksanen et al. 2018), this test is used to quantify variation in multivariate data and provide a system to statistically test for difference. In this test, a matrix of Bray-Curtis distance measures among all sites 
is used to calculate distance from individual points to the group centroid. The distance matrix was then reduced to principle components in order to translate them into Euclidean space. Euclidian distance between data points and distance to group centroid was then calculated from principal component form. To compensate for negative Eigenvalues in this analysis, which represent imaginary distance, an alternative distance equation was used.

An ANOVA (Analysis of Variance) was conducted on distance from each point to its group centroid. This test supplies a corresponding F-value which can be interpreted with a p-value. If overall ANOVA F-value indicated there was a difference, then a Tukey's Honest Significant Difference method was used to compare pairs of orchard groups.

Community composition was then graphed using a non-metric multidimensional scaling (NMDS) method using the vegan R package (Oksanen et al. 2018).

\section{Anosim}

An analysis of similarity (Anosim) test was used to determine statistical difference in community composition among orchard sites within seasonal time periods. Orchard data points were grouped into four seasons: Early Spring (month of April), Late Spring/Early Summer (months of May and June), Midsummer (month of July), and Late Summer/Early Fall (months of August and September). Anosim was calculated using the vegan package in $\mathrm{R}$ (Oksanen et al. 2018). Anosim is a non-parametric, multivariate test which relies on a dissimilarity matrix. Bray-Curtis dissimilarity was calculated for each 
pair of sites and assembled into a matrix. Anosim is conducted on the dissimilarity matrix using rank average among and within grouping variables. Dissimilarity indexes are first ranked then the average rank is calculated for each dissimilarity within each orchard and calculated for the average rank of each dissimilarity among pairs of orchards. These average ranks are then used the calculate the R statistic. The R statistic can range from -1 to +1 with 0 indicating completely random grouping. Negative $R$ values represent a larger average rank of within group values (more dissimilarity) while larger positive $\mathrm{R}$ values represent a smaller average rank within group values compared to among group values (less dissimilarity).

Statistical significance of $\mathrm{R}$ value is assessed using permutations. The values within the data set are permuted and R statistics recalculated for a total 1000 permutations. The distribution is created of $\mathrm{R}$ values and used to assign a p-value to the original data set R statistic.

\section{Correlation Analysis}

Spearman rank correlations were conducted between pollinator community variables and plant community richness and landscape variables. 


\section{Results}

\section{H1 Orchards with a greater species richness of "pollinator-friendly” flowering}

\section{plants will host a greater pollinator richness.}

Pollinator abundance (total number) and richness (number of morpho-species observed) varied considerably over the growing season. Abundance of pollinators peaked in the early spring with the fruit tree bloom, declined in the month of May, then gradually increased over the summer, peaking again in late July until finally tapering off in August and September (Figure 3). Pollinator morpho-species richness also declined in the month of May and increased into July, then declined through the rest of the growing season until September. Overall, 101 orchard observations were recorded over the course of the 2017 field season, representing 1156 individual pollinators and 86 flowering (non-grass) plant species.

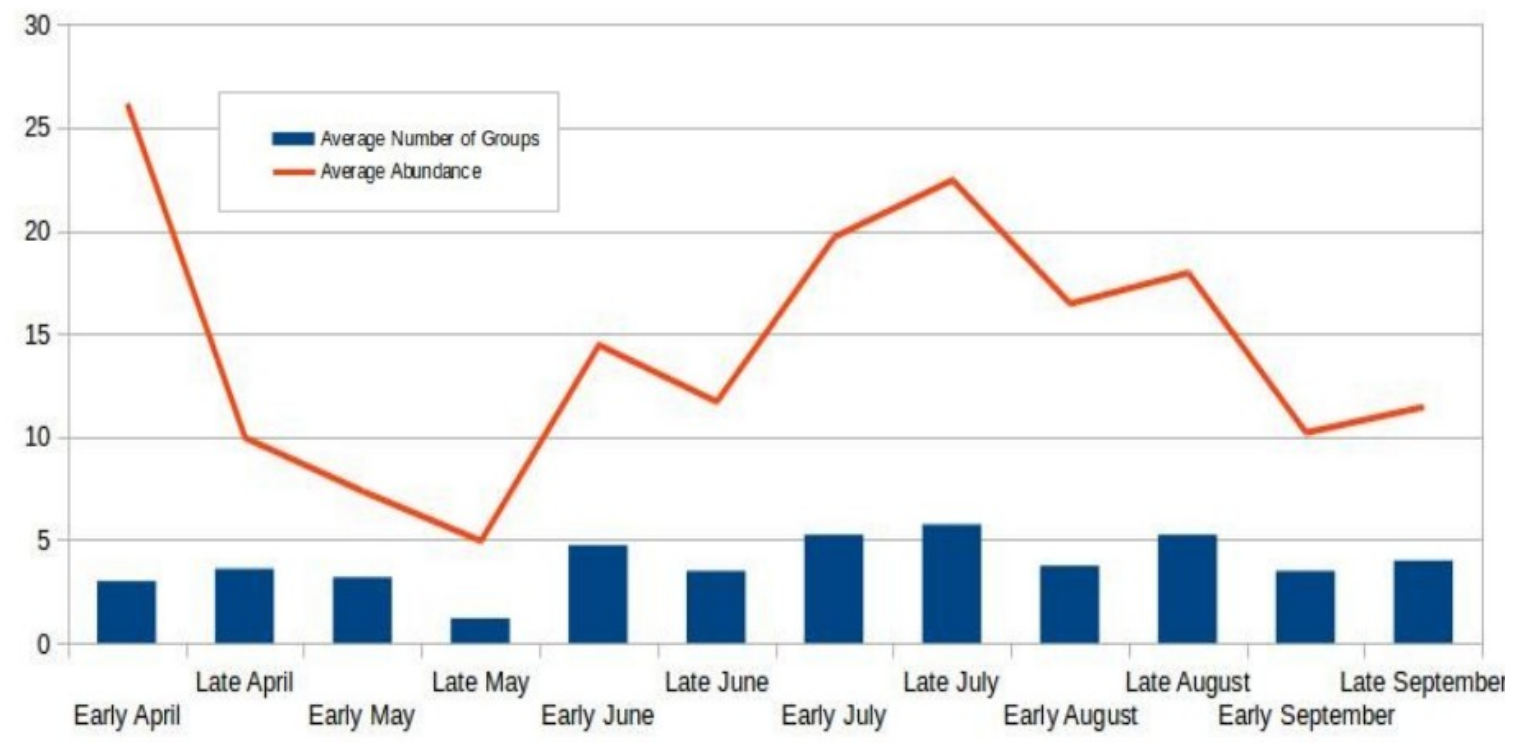

Figure 3. Pollinator morpho-species richness and abundance across the growing season. 
Averaged across the growing season, the orchard with the highest diversity was the Parkrose Orchard with 4.42 groups/observation, and the orchard with the highest abundance was the Green Thumb orchard with an average of 18 pollinators/observation (Table 2). Abundance and diversity were generally covariable. The Parkrose Orchard had the highest diversity but had only the third greatest abundance. The Gabriel Orchard was not included in computing morpho-species richness and abundance for the whole growing season because it did not have any pollinator enhancement plants and was monitored only during the tree bloom period.

Table 2. Orchard pollinator community averages for the whole monitoring period.

\begin{tabular}{|l|l|l|}
\hline Orchard & $\begin{array}{l}\text { Average Number of Pollinators } \\
\text { Morpho-species per Observation }\end{array}$ & $\begin{array}{l}\text { Average Abundance of } \\
\text { Pollinators per Observation }\end{array}$ \\
\hline FOD & 3.83 & 9.33 \\
\hline Green Thumb & 4.08 & 16.75 \\
\hline Parkrose & 4.75 & 16.08 \\
\hline Sabin & 4.00 & 14.25 \\
\hline All Orchards & 4.17 & 14.10 \\
\hline
\end{tabular}

Pollinator communities changed over the growing season with major difference among four seasonal periods (Figure 4). The pollinator community in the early spring (March and April) was dominated by the MDB group, especially those in the genus Andrena. The MDB group was by far the most plentiful with only few other bees active during the fruit tree bloom. Late spring and early summer (May and June) saw the rise in numbers of three major groups the $\mathrm{HB}, \mathrm{BB}$, and TDB. The TDB group experienced their highest numbers during this period coinciding with the blooming of many early season 
flowers and several weedy species. HB and BB groups were generally very active over the course of the whole growing season. Mid-summer (July) saw the second highest abundances of pollinators after the flush during the fruit tree bloom. Midsummer also saw the most equal distribution of pollinator morpho-species with the emergence of the CLB group, as well as an increase in fly and BB abundance. At the end of the season, the community was again dominated by HB and BB, but with additional larger numbers of Fly as well as an increase in SSB abundance.

A
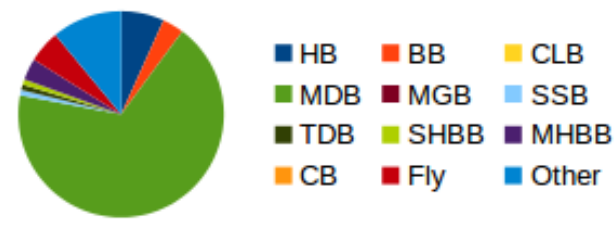

C

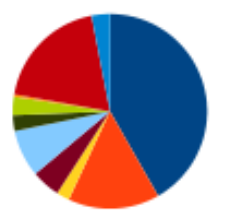

- $\mathrm{HB} \quad \mathrm{BB} \mathrm{CLB}$

MDB $\square \mathrm{MGB}=\mathrm{SSB}$

- TDB =

aB $\quad$ Fly $\quad$ Other
B

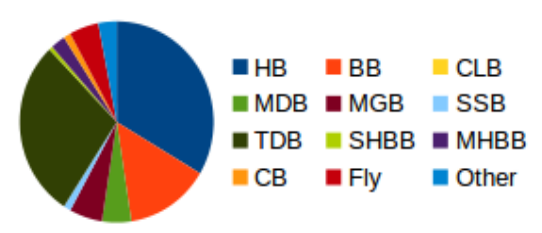

D

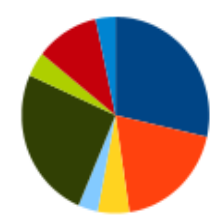

$\|\mathrm{HB}\| \mathrm{BB} \| \mathrm{CLB}$

MDB $\square \mathrm{MGB}=\mathrm{SSB}$

-TDB $\|$ SHBB $=$ MHBB

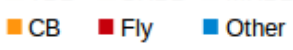

Figure 4. Pollinator community change over time: (A) Early Spring, (B) Late Spring Early Summer, (C) Mid Summer, and (D) Late Summer Early Fall.

There was no statistical difference between orchard communities when comparing within each season. The homogeneity of variance test showed that orchard pollinator communities measured across the seasons had similar variance (Table 3 and Figure 5). 
The average distance from group centroid (Table 3 and Figure 6) showed similar distances within each orchard. An ANOVA test confirmed there was no difference among group variances $(\mathrm{F}$-value $=0.4531, p$-value $=0.7164)$. Seasonal $\mathrm{R}$ statistics for pollinator community varied (-0.042 to 0.16$)$; two seasons had negative R statistics, indicating that the variability within orchard groups was larger than the variability among orchard groups (Table 4). The Anosim permutation method produced non-significant p-values (Table 4).

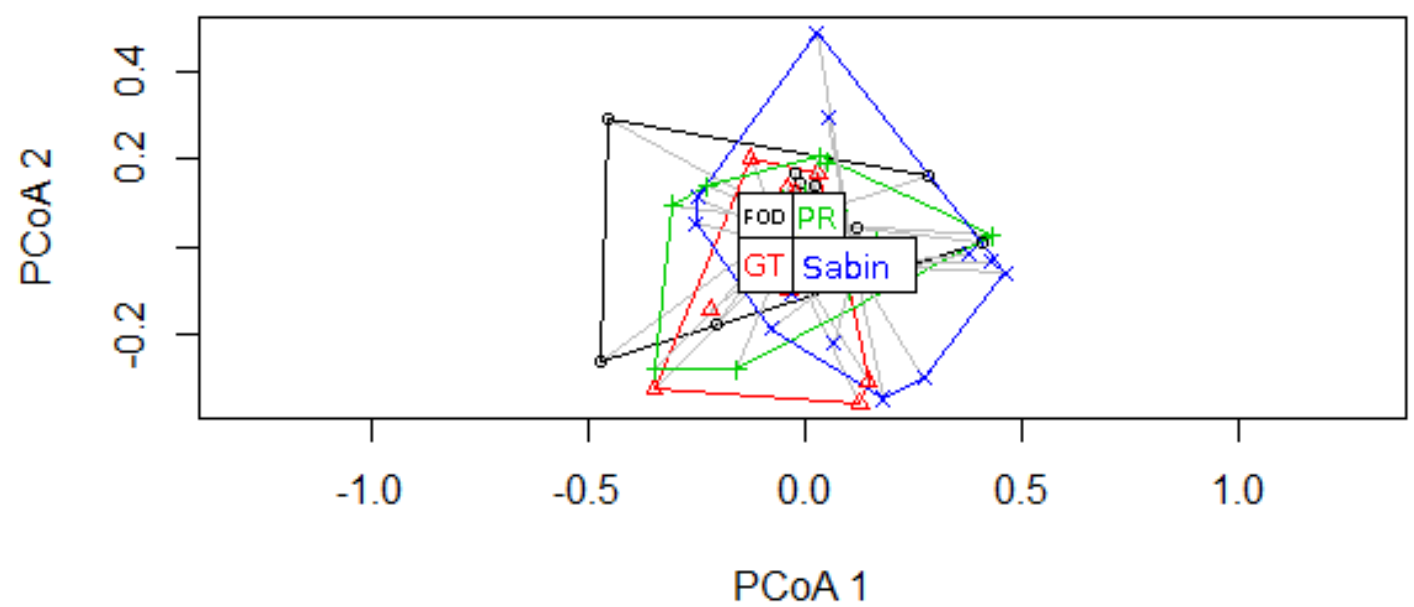

Figure 5. Eigenanalysis of orchard pollinator communities.

Table 3. Average distance to orchard group centroid.

\begin{tabular}{|l|l|l|l|}
\hline FOD & GT & PR & Sabin \\
\hline 0.3957 & 0.4136 & 0.3674 & 0.4248 \\
\hline
\end{tabular}




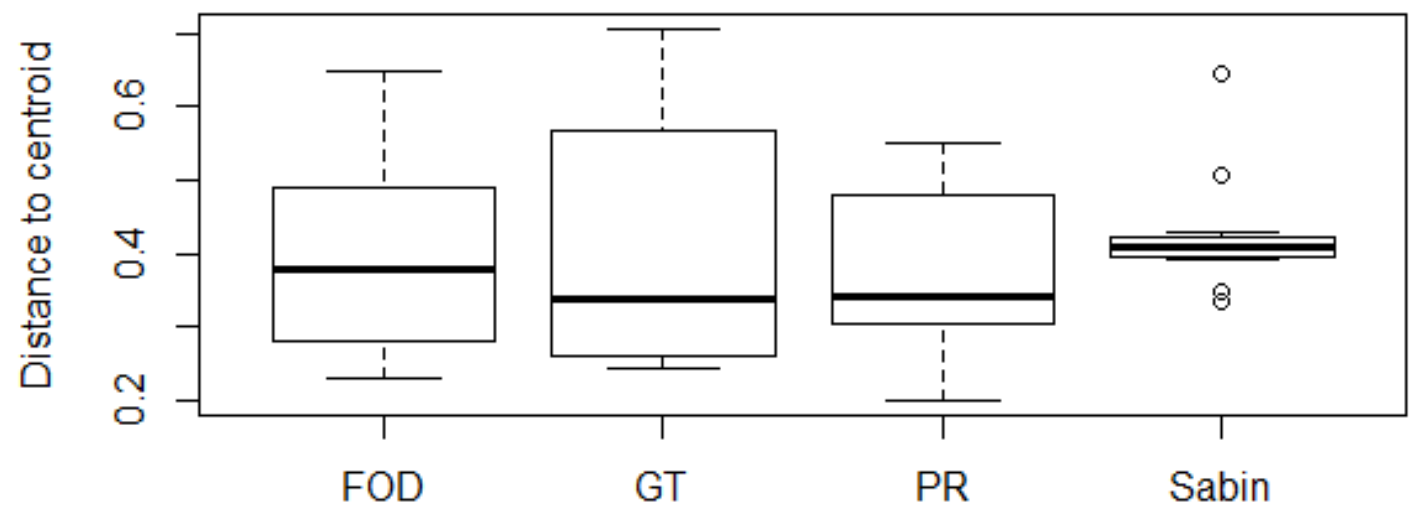

Figure 6. Boxplot of distance to group centroid for each orchard.

Table 4. Anosim results comparing orchards for community difference by season.

\begin{tabular}{|l|l|l|}
\hline Season & Anosim R Statistic & P-value \\
\hline Early Spring & -0.040 & 0.528 \\
\hline Late Spring & 0.14 & 0.167 \\
\hline Midsummer & -0.042 & 0.475 \\
\hline Late Summer & 0.16 & 0.150 \\
\hline
\end{tabular}

The vegetation surveys of each orchard, except Gabriel, showed variation in the number and diversity of flowering plants present intentionally and unintentionally. Plants along each transect represent those which were intentionally planted to provide forage for pollinators and for other benefits. Each orchard has been planted with many different kinds of flowering plants since the time that PFTP has taken over managing them, which has resulted in a total richness of 54 species.

The species found on the orchard transects (Table 6) represent only intentionally planted species and is indicative of a variable approach to pollinator enhancement. Two orchards in particular have received the most pollinator enhancement plants - Parkrose 
and Sabin - and have the highest pollinator enhancement plant species richness per meter (Table 5). While these orchards have the most additional flowering species, they represent different plant communities with only four intentionally planted species in common (Table 5).

There is a range of intentionally introduced species in the orchard sites. A majority would be considered “native” or naturalized to Oregon such as Oregon Grape (Mahonia aquafolium), Yarrow (Achillea millefolium), and Seaside Daisy (Erigeron glauca). The orchards have also been planted with several common flower garden species such as Day Lily (Hemerocallis spp.), Tulip (Tulipia spp.), and Sunflower (Helianthus annuus). The flowers planted at the most orchards include: Hemerocallis spp., Lupinus polyphyllus, Mahonia aquifolium, Ribes spp., Rosmarinus officinalis, and Symphytum officinale (Table $6)$.

Table 5. Orchard transect diversity.

\begin{tabular}{|l|l|l|l|}
\hline Orchard & Transect & Transect richness/meter & Pollinator Friendly Plant \\
& richness & & Richness \\
\hline FOD & 13 & 0.16 & 10 \\
\hline Green Thumb & 20 & 0.25 & 14 \\
\hline Parkrose & 30 & 0.30 & 16 \\
\hline Sabin & 23 & 0.33 & 9 \\
\hline Total & 54 & - & -- \\
\hline
\end{tabular}


Table 6. Intentionally planted orchard flowering plants recorded on transects.

\begin{tabular}{|c|c|c|}
\hline Scientific Name & Common Name & \# Orchards \\
\hline Achillea millefolium* & Yarrow* & 2 \\
\hline Akebia spp. & Akebia & 1 \\
\hline Allium cernuum*+ & Nodding Onion*+ & 1 \\
\hline Amelanchier alnifolia+ & Service Berry+ & 2 \\
\hline Anaphalic margaritacea+ & Pearly Everlasting+ & 2 \\
\hline Anisomeles spp.* & Cat Mint* & 1 \\
\hline Apocynum androsaemifolium & Spreading Dogbane & 1 \\
\hline Aronia spp. & Chokeberry & 1 \\
\hline Bellis perennis & Daisy & 1 \\
\hline Ceanothus thyrsiflorus+ & Blue Blossom+ & 2 \\
\hline Cornus mas & Corinthian Cherry & 1 \\
\hline Cosmos spp. & Cosmos & 1 \\
\hline Cotoneaster spp. & Coton Easter & 1 \\
\hline Crataegus pinnatifida & Chinese Haw & 1 \\
\hline Cynara spp.* & Artichoke* $^{*}$ & 1 \\
\hline Elaeagnus spp. & Goumi & 3 \\
\hline Erigeron glaucus*+ & Seaside Daisy*+ & 1 \\
\hline Eriophyllum lanatum+ & Oregon Sunshine+ & 1 \\
\hline Fragaria spp.* & Strawberry* & 2 \\
\hline Gaultheria shallon+ & Salal+ & 1 \\
\hline Geranium endressii & Geranium & 2 \\
\hline Helianthus annuus* & Sunflower* & 1 \\
\hline Hemerocallis spp. & Day Lily & 2 \\
\hline Holodicus discolor+ & Ocean Spray+ & 1 \\
\hline Hydrangea spp. & Hydrangea & 1 \\
\hline Lavendula spp.* & Lavender* & 2 \\
\hline Lupinus polyphyllus*+ & Lupine*+ & 3 \\
\hline Mahonia aquifolium+ & Oregon Grape+ & 3 \\
\hline
\end{tabular}




\begin{tabular}{|c|c|c|}
\hline Matricaria chamomilla & Chamomile & 1 \\
\hline Melissa officinalis & Lemon Balm & 2 \\
\hline Monarda spp. & Bee Balm & 2 \\
\hline Narcissus spp. & Daffodil & 1 \\
\hline Oemleria cerasiformis + & Indian Plum+ & 1 \\
\hline Origanum vulgrae* & Oregano* & 1 \\
\hline Pentstemon spp.* & Pentstemon* & 1 \\
\hline Pentaglottis sempervirens & Evergreen Bugloss & 1 \\
\hline Phytolacea spp. & Pokeweed & 1 \\
\hline Ribes spp.+ & Currant + & 4 \\
\hline Rosa nutkana+ & Nootka Rose+ & 1 \\
\hline Rosmarinus officinalis* & Rosemary* & 3 \\
\hline Rubus parviflorus+ & Thimbleberry+ & 1 \\
\hline Rubus spectabilis+ & Salmonberry+ & 1 \\
\hline Salidago elongata*+ & Goldenrod*+ & 2 \\
\hline Sambucus racemosa & Elderberry & 2 \\
\hline Sidalcea campestris+ & Checkermallow ${ }^{+}$ & 2 \\
\hline Spiraea douglasii + & Douglas Spirea+ & 2 \\
\hline Symphoricarpos albus+ & Snowberry+ & 1 \\
\hline Symphyotrichum subspicatum+ & Douglas Aster+ & 2 \\
\hline Symphytum officinale & Comfrey & 3 \\
\hline Tulipa spp. & Tulip & 1 \\
\hline Vaccinium corymbosum & Blueberry & 2 \\
\hline Vaccinium ovatum+ & Evergreen Huckleberry+ & 2 \\
\hline Xerophyllum tenax ${ }^{+}$ & Beargrass + & 1 \\
\hline Ziziphus jujuba & Jujube & 1 \\
\hline Total \% listed as pollinator friendly & $29 / 54=54 \%$ & \\
\hline
\end{tabular}

* Listed as non-native perennial or annual pollinator enhancement plant for Oregon (Pendergrass et al. 2008)

+ Listed as a native perennial or annual pollinator enhancement plant for Oregon (Pendergrass et al. 2008) 
The orchard generic vegetation surveys recorded a total plant richness in a stratified random sample within the orchard and found 48 species with a mean plot richness of 2.46 species (Table 7). The Parkrose Orchard had the greatest total number of species, but had a low mean average plot richness and a high species turnover, which is likely the result of large scale wood-chip mulching practices which discourage weedy species.

There were variable correlations between pollinator community data and orchard vegetation surveys. The generic vegetation survey of the whole orchard showed almost no correlation with pollinator community variables $(\rho=0.4)$ which is only just greater than the standard error of 0.365 (Table 8).

For the transect survey of intentional plantings, there was a strong correlation between the average number of morpho-species per observation and orchard transect richness (Spearman rank correlations $\rho=0.8$ ) (Table 8). The total number of "pollinator friendly" plants in the orchard also was strongly correlated with number of morphospecies per observation $(\rho=0.8)$ (Table 8). Pollinator abundance also showed almost no correlation with transect richness $(\rho=0.4)$. These strong correlations provide evidence for H1 that the greater the richness of "pollinator friendly" plants, the greater the richness of pollinators that visit the orchard. 
Table 7. Orchard vegetation survey summary statistics for plant species richness

\begin{tabular}{|l|l|l|l|l|l|}
\hline Orchard & Richness & Mean & SD of & Range & $\begin{array}{l}\text { Total } \\
\text { richness/mean } \\
\text { richness per } \\
\text { plot }\end{array}$ \\
\hline FOD & 19 & 2.23 & 0.22 & $0-5$ & 8.52 \\
\hline Green Thumb & 12 & 1.77 & 0.18 & $1-5$ & 6.78 \\
\hline Parkrose & 28 & 2.10 & 1.49 & $0-6$ & 13.3 \\
\hline Sabin & 20 & 3.73 & 2.39 & $0-10$ & 5.36 \\
\hline All Sites & 48 & 2.46 & 1.77 & $0-10$ & 19.51 \\
\hline
\end{tabular}

Table 8. Spearman Rank Correlation $(\rho)$ between pollinator community and vegetation surveys.

\begin{tabular}{|l|l|l|}
\hline & $\begin{array}{l}\text { Average number of morpho- } \\
\text { species per observation }\end{array}$ & $\begin{array}{l}\text { Average abundance per } \\
\text { observation }\end{array}$ \\
\hline $\begin{array}{l}\text { Transect } \\
\text { Richness }\end{array}$ & 0.8 & 0.4 \\
\hline $\begin{array}{l}\text { "Pollinator } \\
\text { Friendly" } \\
\text { Richness }\end{array}$ & 0.8 & 0.6 \\
\hline $\begin{array}{l}\text { Vegetation } \\
\text { Survey Richness }\end{array}$ & 0.4 & -0.2 \\
\hline
\end{tabular}

H2 Orchards with more potential nearby habitat (within 500 meters) will have higher total pollinator richness and will have higher bumble bee abundance with more potential habitat further (within 2000 meters).

Urbanization metrics showed similarities and differences of landscape variables 
among orchards (Table 9). The Sabin Orchard is the closest to the city center and is located in a dense urban residential area with $78 \%$ of the land zoned as SFR. This orchard also has the most number of road miles within the buffer zones as well as the least amount of ORCA land. However, it does not have the lowest average NDVI value. On the opposite end of the urbanization spectrum, the Gabriel Orchard is surrounded by Gabriel Park (one of the largest in Portland) and has the highest average NDVI values at both scales. However, at the 2000m scale it has only the third most ORCA area and third most number of street miles. It is also in a very residential part of town, though it has a lower percentage of SFR zoning compared to other orchards. Overall, no clear gradient of urbanization exists for these orchards.

Table 9. GIS Analysis of orchards

\begin{tabular}{|l|l|l|l|l|l|l|l|l|}
\hline Orchard & ORCA & Street & SFR \% & Average & ORCA & Street & SFR \% & Average \\
& $2 \mathrm{~km}$ & Length & $2 \mathrm{~km}$ & NDVI & $500 \mathrm{~m}$ & Length & $500 \mathrm{~m}$ & NDVI \\
& $(\mathrm{mi} \wedge 2)$ & $2 \mathrm{~km}$ & & $2 \mathrm{~km}$ & $\left(\mathrm{mi}^{\wedge} 2\right)$ & $500 \mathrm{~m}$ & & $500 \mathrm{~m}$ \\
\hline FOD & 1.50 & 96.2 & 0.86 & 113 & 0.047 & 8.4 & 0.41 & 112 \\
\hline Gabriel & 0.49 & 114 & 0.67 & 123 & 0.12 & 6.7 & 0.5 & 127 \\
\hline (spring only) & & & & & & & & \\
\hline Green & 0.33 & 131 & 0.83 & 115 & 0.056 & 7.4 & 0.05 & 115 \\
\hline Thumb & & & & & & & & \\
\hline Parkrose & 0.67 & 97.9 & 0.67 & 110 & 0.018 & 7.0 & 0.094 & 114 \\
\hline Sabin & 0.17 & 151 & 0.78 & 114 & 0.009 & 10.5 & 0.07 & 116 \\
\hline
\end{tabular}


Correlating pollinator morpho-group richness and abundance with landscape variables produced mixed results (Table 10). The street length within 500m was moderately negatively correlated with number of morpho-groups $(\rho=-0.8)$ and average abundance $(\rho=-0.6)$. At a range $2000 \mathrm{~m}$, the number of total bumble bees had a moderately negative correlation with percentage single family residential area $(\rho=-0.8)$ and with NDVI ( $\rho=-0.8)$. The tiny dark bee morpho-group had a moderate negative correlation with the amount of ORCA land with 500m $(\rho=-0.6)$. Correlations of $-0.4<\rho<0.4$ were considered non-significant.

Table 10. Spearman rank correlations between pollinator community and urban landscape characteristics. Standard error for correlations of sample size 4 is 0.365 .

\begin{tabular}{l|l|l|l} 
& $\begin{array}{l}\text { Average Number of } \\
\text { Groups }\end{array}$ & Average Abundance & Total TDB \\
ORCA500 & 0 & 0.4 & -0.6 \\
SL500 & -0.8 & -0.6 & -0.4 \\
SFR500 & -0.2 & -0.4 & -0.4 \\
NDVI500 & 0.2 & 0.4 & 0.4
\end{tabular}

\begin{tabular}{l|l|} 
& Total Bumblebees \\
ORCA2k & 0 \\
SL2k & 0 \\
SFR2k & -0.8 \\
NDVI2k & -0.8 \\
\hline
\end{tabular}


H3 Orchards with a larger abundance of any pollinators in the orchards during the fruit tree bloom period will produce more fruit-lets on average for each fruit tree group; apple, pear, and plum.

Fruit tree canopy volume is influenced by age of the tree and pruning frequency, and has an important influence on overall fruit production. The orchard study sites range in age from 3 years to $>20$ years which can be seen in the overall tree canopy size. The youngest site (Parkrose) has trees considerably smaller than the other four orchards, and because of this, it was not included in the analysis of fruit production. In contrast, the oldest site (Gabriel) has the largest trees by a large margin due to the age of the trees, but is also a reflection of infrequent pruning over several years.

Canopy volume also has an impact on the amount of fruit produced by an individual tree and the amount of floral resources that it provides to potential pollinators. The Gabriel site also produced the largest fruit-set in 2017 and 4-8 times more plums than other orchards (Table 11). On the other end of the spectrum, the Parkrose Orchard is the youngest and clearly had the smallest trees which are overall too young to produce much fruit or provide much floral resource for urban pollinators. 
Table 11. Orchard canopy volume and fruit set.

\begin{tabular}{|l|l|l|l|l|l|l|l|}
\hline Orchard & Number & Average & Average & Average & Average & Average & Average \\
& of Trees & Apple Tree & Pear Tree & Plum Tree & \# Apples & \# Pears & \# Plums \\
& & Volume & Volume & Volume & per & per & per \\
\hline FOD & 46 & 50.6 & 36.5 & 64.9 & 3.9 & 5.8 & 2.7 \\
\hline Gabriel & 24 & 217.6 & 232.0 & 245 & 13.5 & 14.5 & 40.3 \\
\hline Green & 54 & 165.4 & 30.5 & 134.3 & 3.7 & 8.7 & 3.6 \\
\hline Thumb & & & & & & & \\
\hline Parkrose & 32 & 6.6 & 4.0 & 8.4 & 2.5 & 0 & 0.1 \\
\hline Sabin & 23 & 131.3 & 32.2 & 68.5 & 7.5 & 6.7 & 10 \\
\hline Overall & 33.25 & 130.2 & 74.9 & 114.1 & 6.8 & 7.5 & 13.5 \\
\hline Average & & & & & & & \\
\hline
\end{tabular}

Presence of pollinators is required for producing fruit on orchard trees. I hypothesized that orchards with a larger abundance of any pollinators in the orchards during the fruit tree bloom period will produce more fruit-lets on average for each fruit tree group of apple, pear, and plum (H3). During the spring season, the average abundance of pollinators at each orchard varied widely from an average of 7 per observation to as many as 30.5 per observation (Table 12).

Correlations of pollinator community data with orchard fruit set produced mixed levels of correspondence between pollinator communities and fruit set. The number of pears and number of plums here strongly correlated with the abundance of pollinators ( $\rho=1$ and $\rho=0.8$ respectively) (Table 13 ). Number of pears was also strongly correlated 
with number of morpho-species. Apple production had almost no correlation with pollinator community (Table 13). Overall, tree canopy volume also correlated strongly with fruit set on pear and plum trees and almost not at all with apple trees (Table 14).

Table 12. Pollinator community averages in the spring season.

\begin{tabular}{|l|l|l|}
\hline Orchard & $\begin{array}{l}\text { Average Number of } \\
\text { Pollinators Groups per } \\
\text { Observation }\end{array}$ & $\begin{array}{l}\text { Average Abundance of } \\
\text { Pollinators per } \\
\text { Observation }\end{array}$ \\
\hline FOD & 2.5 & 7 \\
\hline Gabriel (spring only) & 3 & 18 \\
\hline Green Thumb & 4 & 30.5 \\
\hline Parkrose & 3 & 9.5 \\
\hline Sabin & 4 & 26 \\
\hline Overall & 3.3 & 18.2 \\
\hline
\end{tabular}

Table 13. Spearman rank correlation between fruit set and number of bee groups and abundances and orchard fruit production. Standard error $=0.365$.

\begin{tabular}{|l|l|l|}
\hline & Average number of groups & Average abundance \\
\hline \# of apples per branch & -0.2 & 0.4 \\
\hline \# of pears per branch & 0.8 & 1 \\
\hline \# of plums per branch & 0.4 & 0.8 \\
\hline
\end{tabular}

Table 14. Spearman rank correlation between fruit set and tree size

\begin{tabular}{|l|l|l|l|}
\hline & \# apples per branch & \# pears per branch & \# pears per branch \\
\hline $\begin{array}{l}\text { Average Tree } \\
\text { Volume }\end{array}$ & 0.4 & 1 & 0.8 \\
\hline
\end{tabular}




\section{Validation of species identification}

Volunteers submitted 117 photographs of pollinators for validation out of a total of 567 observations accounting for $21 \%$ of all observations. The misclassification rate was $11 \%(13 / 117)$ and $3 \%(4 / 117)$ of the photos were not able to be validated. The most misclassified morpho-species were: Striped Sweat bee, Honey bee, Cukoo Bee, and Metallic Hairy Belly Bee each with two classification errors each. The groups with no classification error were: Bumble Bee, Tiny Dark Bee, Chap Leg Bee, and Striped Hairy Belly Bee.

\section{H4 Volunteer participation in this project will increase participant intention to promote pollinator habitat in their residential yard space.}

The degree to which participation in this project increased volunteer intention to

promote pollinator habitat is inconclusive. In response to the statement, "I will participate in other pollinator conservation efforts in the future (including at your own home)," the average response to this question on the post-project survey was 7.8 out of 10 . In the midproject survey participants had an average response of 4.75 out of 5 when asked if they had “planted specific flowers I hoped will attract pollinators,” which was the highest rated response among five choices.

For demographic information, volunteer income ranged from between $\$ 25,000$ and \$125,000 with two declining to answer. Respondents were between 36 and 75 years old. The ethnicity of the volunteers were white (4 responses) and Latino (1 response). All of the participants had a Bachelor's degree and one participant had a PhD. 


\section{Discussion}

\section{Pollinator Richness and Abundance Patterns}

Urban pollinator biodiversity is driven by many factor and recent work has highlighted the importance of floral diversity and local habitat variables to pollinator richness and abundance. The PFTP orchards have been modified to increase their floral diversity with the informal goal of increasing pollinator biodiversity. The driving question of this research (H1) was whether or not orchards with a greater number and variety of “pollinator friendly” plants would host a greater pollinator richness.

The five orchard sites all displayed similar patterns of seasonal pollinator richness and abundance. Fruit tree bloom in April brought a large number of pollinators, which was followed by a lull in May as spring blooming flowers finish blooming. The summer months of June and July saw a new variety of plants bloom and a second peak abundance, followed by a decline through August and September. This seasonal pattern was present across all orchards despite local variations in diversity and abundance (Figure 3 and Table 2).

Pollinator community composition, using morpho-species, changed significantly over the growing season (Figure 4) in response to different bloom times across flowering plants. Community composition of pollinators among orchard sites was tested for difference and revealed that each orchard had similar variance in community across the growing season and no significant difference in pollinator community composition (Table 3 and Figure 5,6). Orchards were also compared to each other during each of four 
growing season periods with anosim results that showed no difference in community composition between orchards (Table 4). This result suggests that the morpho-species were represented similarly relative to each other across all sites. Overall, there may be healthy populations of the different pollinator groups in the urban Portland area. However, this result may also be an artifact of the morphospecies designation used with volunteers, or may be due to methodological issues. The morpho-species protocol used in this study hides specialist bees by mixing them together into groups that have the same shape but different functional needs. This protocol does not have the taxonomic resolution to determine specialist species. This information would be necessary to determine the preference of specific bee species.

Floral richness and pollinator richness correlations showed variable relationships (Table 5 and 7). The orchard with the highest transect plant diversity—Parkrose—had 28 flowering plant species and the highest average number of pollinator groups per observation. The FOD orchard had the opposite relationship with the lowest transect floral richness and the lowest average number of pollinator groups per observation. The Gabriel Orchard had the overall lowest average number per observation, and there were no additional flowering plants at that orchard, as well as a limited numbers of observations (only taken in April and May).

The richness of pollinator-friendly plants had a positive correlation with the average number of morpho-species per observation $(\rho=0.8)$ and almost no correlation with generic floral richness $(\rho=0.4)$ (Table 8). This correlation supports my first hypothesis and provides evidence for the attractiveness of the plants on the transect, 
many of which were designated as "pollinator friendly".

Pollinator abundance showed a different relationship with the number of flowering plant species. The Parkrose Orchard had the highest average diversity, but only the third highest average abundance whereas the Green Thumb Orchard had the highest average abundance and second highest diversity. The FOD Orchard, however, had the lowest average diversity and average abundance. This trend is likely caused by large numbers of MDB's in the early part of the season which raised the average abundance overall. The GT Orchard had the most number of trees of any orchard and during peak tree bloom had the highest single abundance day. On the other hand, the Parkrose Orchard had young trees with limited bloom times and quantity so it did not attract large numbers of MDBs like the other orchards. The average abundance per observation showed almost no correlation with either transect richness or vegetation survey richness (Table 8). One limitation of this study is that a vegetation survey with only presence/absence data does not provide information about floral patch size or about how many flowers individual inflorescences there are at the study sites. The orchard sites in general do not have large patches of flowers that may be required to make a site appealing to many pollinators.

In the context of this study, the morpho-species protocol used may not have the taxonomic resolution to determine community difference although difference in community composition may still exist among orchards. Additionally, my choice of how to divide my observations into seasons may have created inappropriate comparisons for the pollinator community. 
A third limitation to my analysis was that the homogeneity of variance test could not be conducted within each seasonal window because of small sample size per orchard (2 or 4 samples per orchard per season). This presents potentially inappropriate comparisons among orchards across the whole growing season.

Urban areas likely act as a filter for generalists bees (Hernandez et al 2009) as compared with specialist bees. The combination of high plant beta diversity and insufficient clumps of the plants and nesting resources required by specialist bees means that they have a hard time living here. This bias toward generalist bees likely translates to pollinator preference to those plants that provide the largest or most stable nectar and pollen rewards. This is especially visible with the orchard fruit trees as well as some other plants with large number of blooms such as Douglas Aster (Symphyotrichum subspicatum). Certain weedy species such as Daucus carota and Senecio vulgaris were also highly visited in the orchards, implying that these species are significant sources of nectar for many bees, including honey bees. Reducing the frequency of mowing at orchard sites may preserve some of the weedy flowering species to provide floral resources in between major bloom times for other plants in the orchard.

\section{Landscape Level Analysis}

I had hypothesized that presence of potential habitat would have a positive correlation with pollinator richness, but my results were mixed (H2). Pollinators are highly mobile and rely on the distribution of forage and nesting areas within their habitat range. Within the urban context, the plant community can be incredibly variable and this can have significant influence on pollinator gene flow, foraging, and nesting behavior. 
Based on previous research (Davis et al., 2010; Threfell et al, 2015) quantifying urban landscape characteristics at ranges of up to $2000 \mathrm{~m}$ have been used to determine correlations with pollinator distributions.

Only the street length variable showed significant correlation with pollinator variables, but both the percentage of single-family residential zoning and the NDVI at 2000m showed significant correlation with bumblebee abundance. The number of miles of street within $500 \mathrm{~m}$ had a strong, negative correlation $(\rho=-0.8)$ with the number of morpho-species and a moderate negative correlation $(\rho=-0.6)$ with average abundance (Table 8). Street length is one of the most common indicators of urbanization used in many pollinator studies, but it does not always have a uniformly negative association. In urban Portland, however, neighborhoods with more streets correspond with a decrease in the richness and abundance of pollinators. In addition, there is a moderate negative correlation ( $\rho=-0.6)$ between the amount of ORCA land and the abundance of bees in the tiny dark bee group (Table 3.10.1). It is difficult to speculate why this correlation exists, yet the smallest bees would be most vulnerable to a smaller scale effect within 500m from their forage areas since they cannot fly as far to find resources.

Individual differences in the landscape surrounding each orchard can help explain why landscape variables alone do not explain pollinator communities. The Gabriel Orchard is surrounded by a forested area, as well as large open grass fields which provide large open areas for nesting. It is possible to infer there is adequate Andrena habitat nearby because of the abundance of this bee during the tree bloom time as well as heavy fruit set thanks to ample visitation. Conserving this pollinator may be an important goal, 
and actions which do not disrupt Andrena nesting habitat would be beneficial.

In contrast, the Sabin Orchard is arguably the most urban with the lowest amounts of ORCA area, and highest amount of road miles at both scales. Although this orchard is the smallest of the five, it is well established. This orchard had an above average fruit harvest compared to the other sites as well as a high richness and abundance of pollinators.

My analysis shows only a limited influence of landscape variables which suggests that local, small scale habitat variables have more of an influence on the pollinator community. Although I hypothesized that landscape variables at 2000m would influence only the largest class of bees, I found strong negative correlations with percentage of single-family residential zoning and NDVI with total bumble bee abundance. This strong negative correlation has no obvious reason because it is contrary to other research, which indicates that single-family housing can have floral resources for bees and the general trend that the "greener" an area is, the more likely it is to have abundance flowers. More research, especially including mark and recapture techniques, could be useful in determining where bumble bees are foraging or nesting. This echoes the lack of clear landscape influences found by other researchers.

This landscape analysis is limited to only a few readily quantifiable measures of urbanization and perhaps only to a subset of bees. Urbanization takes many forms and the data available at this scale largely only reflects where there is a lack of habitat and forage, but is inaccurate about the quality of that habitat. Urban bees are surprisingly adaptable, considering they are able to survive even only in community gardens in the heart of New 
York City as Matteson et al. (2008) described. Overall, NDVI is also a common metric of urbanization is not sensitive to detect plant species which might be more suitable to bees, which implies two areas with similar NDVI may have drastically different pollinator communities because of the plants specific to each area.

\section{Orchard Fruit Production}

Fruit production is a primary objective of any fruit orchard, yet the data indicates that encouraging pollinators has variable impact on overall fruit production. I hypothesized (H3) that having a larger abundance of pollinators during the fruit tree bloom time will correlate with greater fruit production. This was based on the common approaches to increasing fruit production (bringing in more bees), and the connection with the goals of pollinator gardening (e.g. to bring in more pollinators to an area). Comparing abundance data with fruit production showed there is a strong correlation between both pear production and average abundance $(\rho=1)$ and with plum production $(\rho=0.8)$ and average abundance. There is almost no correlation with apple production and pollinator abundance (Table 8).

There are several explanations for this finding. Orchard tree production is influenced by many variables besides planting under-story flowers, including climate, soil, variety of tree, bloom timing, and pruning practice. It is also common for fruit tree to exhibit “alternative bearing” where they will produce large crops on alternative years despite adequate pollination and other favorable factors. Some or all of these variables can influence PFTP orchard production. Likely the most important factor in this analysis is the age and size of the trees. Generally, trees produce more fruit per branch as they age 
if they are well cared for and pruned to encourage fruiting. The two oldest orchards (Gabriel and Green Thumb) have largest tree canopy volume and also fruit production. Average tree volume is also strongly correlated with pear and plum production, and very weakly correlated with apple production (Table 12). Successful pollination is a prerequisite for fruit production, but considering the distribution of fruit production, it is difficult to determine the relative influence of adequate pollination verses tree age. More research would be needed to determine whether having better pollination in the orchards would increase fruit production or whether pollination is adequate, but there are strong effects from other variables on fruit production.

It is difficult to generalize about how the presence of pollinators effects fruit production for several reasons. This data only accounts for one year's worth of observations, and there is no true control or baseline data from which to judge whether fruit production has increased as a result of pollinator enhancements. The fruit-set counting methods may also only provide an incomplete picture of an individual trees production due to randomized and limited sampling of fruit-lets. Averaging fruit production across all members of apple, pear, and plum does not capture differences in fruit production which are characteristic of particular varieties. Additionally, this work does not capture information about the efficiency of pollination among groups of pollinators. More work should be done to determine the effectiveness of pollen transfer per visit. It has been shown, for example, that the blue orchard mason bee is highly effective at pollinating fruit trees, yet there is no data to determine how responsible the mason bee is for pollination, considering it likely had help from other bees, including 
Andrena. This bee in particular was the most abundant bee observed during the spring bloom period and was almost exclusively observed on fruit trees. It seems to have developed a niche in the urban ecosystem by taking advantage of blooming fruit trees.

Supporting Andrena and Osmia (mason bees) by planting diverse, early blooming flowers may be an important management strategy because it provides a variety of nectar and pollen sources for these bees most responsible for pollinating the fruit trees.

\section{Community Science}

Volunteer collection effort and education was a major part of this project. This project could have been conducted without volunteer help, but incorporating volunteers and PFTP benefited the project in several ways. The reciprocal relationship between this research and PFTP ensured that both parties were benefiting. This and other community science projects engage in the co-production of knowledge, which serves to benefit the research objectives, as well as developing expertise within the community. Developing this relationship allows the knowledge that is generated to benefit everyone and make the project more impactful, and therefore more justifiable in terms of funding the project. In 2018, PFTP transitioned to be a completely volunteer run organization. Building a volunteer base for this project was important because it educated people about the importance of pollinators and this knowledge can now help inform them in their continued management of the orchards to meet their pollinator conservation goals.

Project surveys showed that project volunteers have significant intention to support pollinators in the future. Statistical analysis was not possible on volunteer survey results, but when asked about their intention to promote pollinator habitat in their 
residential yard the average response was 7.8 out of 10 . The mid-project survey did not specifically ask how likely a volunteer was to promote pollinator habitat in their own yards, but when asked wither they had "planted specific flowers I hoped will attract pollinators," the average response was 4.75 out of 5 . This indicates that volunteers had substantial previous experience with planting flowers, potentially for pollinator enhancement. It is not clear whether participation in this project improved their intention to promote pollinators. Granted, it is difficult to add additional support to an intention when one's support is already high. The survey respondents were also biased to being those who participated the most in the project and clearly cared much more about pollinators to begin with. Results might likely have been different if more people had completed the survey to better represent everyone who participated. Overall, my survey results do not support my fourth hypothesis that participation will increase intention among volunteers to promote pollinator habitat in their own yards.

Volunteers gained something from being involved, especially having increased awareness of pollinators and confidence in identification of pollinators. Volunteers also benefited from being involved in a science project, but to a lesser extent than compared to benefits from learning pollinator identification. The surveys also showed that volunteers get information on pollinators from several sources.

Community science involvement in pollinator monitoring can produce a sufficient quantity of data which is of decent quality. This project found an $11 \%$ mis-classification rate among volunteer collected data, which is encouraging provided that this is the first year of this project and that volunteers will generally get better over time. It is likely that 
the error rate overall is lower considering that the most abundant bee in the orchard was the honey bee and bumble bee, which are readily identified by volunteers. Most misclassifications came from the other, less abundant groups. Overall, with continued training, project volunteers will improve their mis-classification rate and build an important source of data.

\section{Focus Group Results and Discussion}

The focus groups revealed two major themes regarding volunteer participation. The first was that all of the participants had significant previous experience with pollinators or otherwise already felt they were important prior to participating in this project. The second theme, complementary to the first theme, was that the volunteers all agreed that their most important takeaway from the project was that they learned that there are many more native bees besides honey bees and bumble bees.

Volunteer's previous experience was varied. One volunteer had grown up next to an orchard and had seen firsthand how the trees needed to be pollinated, while another volunteer was a master gardener. Every volunteer had significant personal gardening experience which, at a minimum, exposed them to the necessity of crop pollination. It was important to them to have had the firsthand knowledge and personal observation with the bees.

The volunteers were excited to share reflections on all the different kinds of pollinators they observed, even if they only used the morpho-species classification. Many volunteers agreed that they did not have exposure to groups of bees besides honey and bumble bees. In the words of one volunteer, this project "blew the lid off" of their 
preconceived ideas about pollinator biodiversity.

These results suggest that volunteers are motivated to participate in a biomonitoring projects only if they have significant, pre-established connection or interest in the organism beings studied. It may be the case that organisms that are difficult to identify species, such as bees or birds, especially need this significant prior experience to drive them to get more exposure to the substantial biodiversity of these groups. This is important to consider when recruiting future volunteers because the researcher is much more likely to be well-received when interacting with people who already are on board with learning about pollinators. On the other hand, it suggests that engaging in a biomonitoring project such as this is a "harder sell" for those without significant previous experience. Monitoring projects such as this are vitally important for conservation efforts; however, reaching and engaging new people in caring about pollinators or some other organism is a major challenge.

Volunteers are also likely to appreciate the personalized attention and specific information on how to differentiate the kinds of pollinators. From the perspective of the volunteer, they are novices when it comes to pollinator identification and need and want extra help in learning the protocol. Moving forward, more field-based learning will be important to retain and adequately train volunteers for this and other similar projects.

\section{Future Research}

This work is an observational study of the association between plants and pollinators in an urban area, but is a starting point for more structured and systematic study of plant "attractiveness" for pollinators. More research is needed to understand why 
bees would be attracted to certain plants and to quantify "attractiveness" in terms of nectar reward or pollen nutrition. This work can have important conservation value for pollinators as urban areas are seen are more of a refuge for pollinators as much of their habitat is degraded elsewhere.

The issue of matrix permeability also needs to be addressed in a more substantial way. Many authors suggest that to sustain populations and reduce the effects of inbreeding, the permeability of the urban matrix will need to be increased. Island biogeography suggests that all species need stepping stones for populations to move from one area to another (Hanski 1994). For bees that live in and around cities, the scale for these stepping stones seems to be within the 0.5 to $2 \mathrm{~km}$ scale, including different habitat features such as open space, access to water, and forested areas. Greater amounts of these features within cities may likely support larger bee populations.

Given these general trends, an index of urban permeability for bees may be a useful metric for cities to use when considering development. Additionally, establishing threshold values for landscape features would help in establishing bee-friendly city planning criteria (Pardee and Philpott 2014). Urban permeability is a key factor to determine and will be unique for each city and species, but utilizing the results of this literature can help urban dwellers better care for pollinators. 


\section{Conclusion}

Monitoring at PFTP orchard sites provided important data points in an ongoing exploration of the urban conservation of pollinators and the power of community science. The findings from this study have produced several important management recommendations for PFTP staff and volunteers as they manage their orchards.

The first major finding is that pollinator communities are consistent across varied orchard sites, which suggests that a diverse community of pollinators already exists and are worth conserving. The bee genus called Andrena seems to play an important role in the pollination of fruit trees. It will be important to support them by not disturbing their nesting area and by providing them with early spring flowers to supplement the fruit tree blossoms.

In regards to plants at the orchard sites, the observations suggest that increasing the variety of under-story plants increases the diversity of the pollinator community. Orchards with many different flowering plants attracted bees with different nectar and pollen nutrients. Notably, "weedy” species were visited by a wide range of pollinators, especially in the late summer after many of the midsummer plants finish blooming. Mowing less, when possible, can provide floral resources for pollinators.

The Pollinators Count! project produced an important framework for PFTP to use as a way to educate and engage volunteers. Community science is gaining momentum in many aspects of biodiversity conservation and Pollinators Count! is an example that volunteer scientists can monitor pollinators to an acceptable degree of accuracy. This project also provided some lessons on volunteer motivation and how to improve 
trainings. Volunteers must have a significant prior interest in pollinators in order to participate regularly. They also need hands on, guided experience monitoring in the field in order to gain confidence in their identification. The community aspect of the project is important to maintain through regular, timely communication and incentives to do good work and volunteer often. 


\section{References}

Antonini, Y., R. P. Martins, L. M. Aguiar, and R. D. Loyola. 2013. Richness, composition and trophic niche of stingless bee assemblages in urban forest remnants. Urban Ecosystems 16:527-541.

American Fact Finder-Community Facts. (n.d). https://factfinder.census.gov/faces/nav/jsf/pages/community_facts.xhtml

Brown, M. J. F., L. V. Dicks, R. J. Paxton, K. C. R. Baldock, A. B. Barron, M.-P. Chauzat, B. M. Freitas, D. Goulson, S. Jepsen, C. Kremen, J. Li, P. Neumann, D. E. Pattemore, S. G. Potts, O. Schweiger, C. L. Seymour, and J. C. Stout. 2016. A horizon scan of future threats and opportunities for pollinators and pollination. PeerJ 4:e2249.

Burghardt, K. T., D. W. Tallamy, and W. Gregory Shriver. 2009. Impact of Native Plants on Bird and Butterfly Biodiversity in Suburban Landscapes. Conservation Biology 23:219-224.

Calderone, N. W. 2012. Insect Pollinated Crops, Insect Pollinators and US Agriculture: Trend Analysis of Aggregate Data for the Period 1992-2009. PLOS ONE $7: e 37235$

Cane, J.H., R.L. Minckley, L. Kervin, and T.H. Roulston. 2006. Complex responses within a desert bee guild (Hymenoptera: Apiformes) to urban habitat fragmentation. Ecological Application 16:632-644.

Davis, E. S., T. E. Murray, Ú. Fitzpatrick, M. J. F. Brown, and R. J. Paxton. 2010. Landscape effects on extremely fragmented populations of a rare solitary bee, 
Colletes floralis. Molecular Ecology 19:4922-4935.

Dresner, M., and A. Moldenke. 2017. Gardening for Wildlife: Tree canopy and smallscale planting influences on arthropod and bird abundance. Cities and the Environment (CATE) 10.

Droege - Droege 2007 CS Conference.pdf.

Foster, G., J. Bennett, and T. Sparks. 2017. An assessment of bumblebee (Bombus spp) land use and floral preference in UK gardens and allotments cultivated for food. Urban Ecosystems 20:425-434.

Frankie, G., R. Thorp, J. Hernandez, M. Rizzardi, B. Ertter, J. Pawelek, S. Witt, M. Schindler, R. Coville, and V. Wojcik. 2009. Native bees are a rich natural resource in urban California gardens. California Agriculture 63:113-120.

Frankie, G. W., and L. E. Ehler. 1978. Ecology of insects in urban environments. Annual Review of Entomology 23:367-387.

Garbuzov, M., and F. L. W. Ratnieks. 2014. Quantifying variation among garden plants in attractiveness to bees and other flower-visiting insects. Functional Ecology 28:364-374.

Ghazoul, J. 2005. Buzziness as usual? Questioning the global pollination crisis. Trends in Ecology \& Evolution 20:367-373.

Gibbs, J. 2011. Revision of the metallic Lasioglossum (Dialictus) of eastern North America (Hymenoptera: Halictidae: Halictini.). Zootaxa 3073:1-216.

Goddard, M. A., A. J. Dougill, and T. G. Benton. 2010. Scaling up from gardens: biodiversity conservation in urban environments. Trends in Ecology \& Evolution 
25:90-98.

Hall, D. M., G. R. Camilo, R. K. Tonietto, J. Ollerton, K. Ahrné, M. Arduser, J. S. Ascher, K. C. R. Baldock, R. Fowler, G. Frankie, D. Goulson, B. Gunnarsson, M. E. Hanley, J. I. Jackson, G. Langellotto, D. Lowenstein, E. S. Minor, S. M. Philpott, S. G. Potts, M. H. Sirohi, E. M. Spevak, G. N. Stone, and C. G. Threlfall. 2017. The city as a refuge for insect pollinators: Insect Pollinators. Conservation Biology 31:24-29.

Hanley, M. E., A. J. Awbi, and M. Franco. 2014. Going native? Flower use by bumblebees in English urban gardens. Annals of Botany 113:799-806.

Hanski, I. 1994. Patch-occupancy dynamics in fragmented landscapes. TREE.

Hatfield, R. G., and G. LeBuhn. 2007. Patch and landscape factors shape community assemblage of bumble bees, Bombus spp. (Hymenoptera: Apidae), in montane meadows. Biological Conservation 139:150-158.

Hernandez, J., G. Frankie, and R. Thorp. 2009. Ecology of Urban Bees: A Review of Current Knowledge and Directions for Future Study. Cities and the Environment (CATE) 2.

Hostetler, N. E., and M. E. McIntyre. 2001. Effects of urban land use on pollinator (Hymenoptera: Apoidea) communities in a desert metropolis. Basic and Applied Ecology 2:209-218.

Jha, S., and C. Kremen. 2013. Urban land use limits regional bumble bee gene flow. Molecular Ecology 22:2483-2495.

Kremen, C., K. S. Ullman, and R. W. Thorp. 2011. Evaluating the Quality of Citizen- 
Scientist Data on Pollinator Communities. Conservation Biology 25:607-617.

Leong, M., L. C. Ponisio, C. Kremen, R. W. Thorp, and G. K. Roderick. 2016. Temporal dynamics influenced by global change: bee community phenology in urban, agricultural, and natural landscapes. Global Change Biology 22:1046-1053.

López-Uribe, M. M., S. J. Morreale, C. K. Santiago, and B. N. Danforth. 2015. Nest Suitability, Fine-Scale Population Structure and Male-Mediated Dispersal of a Solitary Ground Nesting Bee in an Urban Landscape. PLOS ONE 10:e0125719.

Luck, M., and J. Wu. 2002. A gradient analysis of urban landscape pattern: a case study from the Phoenix metropolitan region, Arizona, USA. Landscape Ecology 17:327-339.

Matteson, K. C., J. S. Ascher, and G. A. Langellotto. 2008. Bee Richness and Abundance in New York City Urban Gardens. Annals of the Entomological Society of America 101:140-150.

McKinney, M. L. 2008. Effects of urbanization on species richness: A review of plants and animals. Urban Ecosystems 11:161-176.

Meyer, William B. ; Turner, B. L. 1992. Human Population Growth and Global LandUse/Cover Change. Annual Review of Ecology and Systematics. Vol.231(1), p.39-61

Minnerath, A., M. Vaughan, E. Mader. 2014. Maritime Northwest Citizen Science Monitoring Guide for Bees and Butterflies. 2nd Edition. 60 pp. Portland, Ore: The Xerces Society.

NOAA. (n.d.) https://www.ncdc.noaa.gov/IPS/hpd/hpd.html. 
Oksanen, J., F. G. Blanchet, M. Friendly, R. Kindt, P. Legendre, D. McGlinn, P. R. Minchin, R. B. O'Hara, G. L. Simpson, P. Solymos, M. Henry, H. Stevens, E. Szoecs, and H. Wagner. 2018. Vegan: Community Ecology Package. R package versio 2.4-6. https://cran.r-project.org/package=vegan.

Olsen, E. 2011, November 10. City Bees Newly Discovered, Yet Here All Along. https://cityroom.blogs.nytimes.com/2011/11/10/bees/.

Pardee, G. L., and S. M. Philpott. 2014. Native plants are the bee’s knees: local and landscape predictors of bee richness and abundance in backyard gardens. Urban Ecosystems 17:641-659.

Pendergrass, K., M. Vaughan, and J. Williams. 2008. Plants for Pollinators in Oregon. Technical Notes, U.S. Department of Agriculture, Portland, Oregon.

Portland Fruit Tree Project - About. (n.d.). . http://www.portlandfruit.org/about/.

Potts, S. G., J. C. Biesmeijer, C. Kremen, P. Neumann, O. Schweiger, and W. E. Kunin. 2010. Global pollinator declines: trends, impacts and drivers. Trends in Ecology \& Evolution 25:345-353.

Schwarz, K., M. Fragkias, C. G. Boone, W. Zhou, M. McHale, J. M. Grove, J. O’NeilDunne, J. P. McFadden, G. L. Buckley, D. Childers, L. Ogden, S. Pincetl, D. Pataki, A. Whitmer, and M. L. Cadenasso. 2015. Trees Grow on Money: Urban Tree Canopy Cover and Environmental Justice. PLOS ONE 10:e0122051.

Silvertown, J. 2009. A new dawn for citizen science. Trends in Ecology \& Evolution 24:467-471.

Theobald, E. J., A. K. Ettinger, H. K. Burgess, L. B. DeBey, N. R. Schmidt, H. E. 
Froehlich, C. Wagner, J. HilleRisLambers, J. Tewksbury, M. A. Harsch, and J. K. Parrish. 2015. Global change and local solutions: Tapping the unrealized potential of citizen science for biodiversity research. Biological Conservation 181:236-244.

Threlfall, C. G., K. Walker, N. S. G. Williams, A. K. Hahs, L. Mata, N. Stork, and S. J. Livesley. 2015. The conservation value of urban green space habitats for Australian native bee communities. Biological Conservation 187:240-248.

U.S. Census Bureau. 2012. Gazetteer Files. http://www.census.gov/geo/www/gazetteer/files/Gaz_places_national.txt USDA Plant Hardiness Zone Map (n.d). http://planthardiness.ars.usda.gov/PHZMWeb/\# Wilson, J., and O. M. Carril. 2016. The Bees in Your Backyard. Princton University Press.

Wojcik, V. A., and J. R. McBride. 2012. Common factors influence bee foraging in urban and wildland landscapes. Urban Ecosystems 15:581-598.

Zanette, L. R. S., R. P. Martins, and S. P. Ribeiro. 2005. Effects of urbanization on Neotropical wasp and bee assemblages in a Brazilian metropolis. Landscape and Urban Planning 71:105-121. 


\section{Appendix A Volunteer Data Sheet}

\section{Survey Instructions}

Thanks for your help with the Pollinators Count! Project. Below you will find basic instructions and tips for filling out your data sheet.

\section{Do this first}

Begin by filling out the top portion of the sheet with you name, orchard, day, time weather, and temperature. If you can give an accurate temperature please do.

The transect is to be monitored for 10 minutes and the test plot for 5 minutes, 15 minutes for both. Use a stopwatch or your phone to determine your timing.

\section{Filling out the table}

Floral Visitor means the common name of the flower visitor and can refer to all kinds of pollinators including: flies, bees, butterflies, moths, beetles, true bugs, birds, bats, spiders, or wasps.

Description can be a genus name or a description from the morphospecies list: Honey bee, Striped sweat bee, Bumble bee, Tiny dark bee, Chap leg bee, Striped hairy belly bee, Medium dark bee, Metallic hairy belly bee, Metallic green bee, Cuckoo bee Number Observed is the number of each kind of pollinator you found Flower is the name of the flower you where you found the pollinator. Genus is only for bees and include this if you can determine the genus easily. Please take a picture of each different bee you see and we will identify it as best we can. **If you are unsure about how to classify a bee look at your Pocket Guide and informational packet and take a picture. The more pictures we have the better.

Photo ID column is for you to help remember which photos go with each observation. Use this for your own benefit.

\section{Submitting}

Email me a picture of the data sheet and any photos you took during your survey. Naming photos is important to stay organized. Please follow this convention and name them before sending them.

$$
\text { yourlastname_orchardname_date(mm/dd)_plot\#_observation\# }
$$

(if there are more than one photos of a given pollinator add 'a', 'b', 'c', etc. at the end). For example, a photo with the ID: Tyler_FOD_05/25_10b would mean that it was taken by gardener Tyler at the Fruits of Diversity Orchard, the $25^{\text {th }}$ of May, and it was the second photo (b) of the $10^{\text {th }}$ observed pollinator. 


\section{TRANSECT DATA SHEET}

Name:

Date and time:

Orchard (circle one) FOD Gabriel Parkrose Sabin Green Thumb

Sky (circle one): Clear/Partly/Cloudy/Bright Overcast Wind: Calm/Light Air/Light Wind/Light Breeze

Temperature (circle one): 40’s 50’s 60’s 70's 80’s 90’s degree

Bees:

Honey bee

Striped sweat bee

Metallic hairy belly bee

Non-bees:

Bumble bee

Cuckoo bee

Fly,Bird

Tiny dark bee

Metallic green bee

Medium dark bee

Chap leg bee

Striped hairy belly bee

Butterfly

Wasp,True Bug

Moth,Spider

Beetle

\begin{tabular}{|c|c|c|c|c|c|}
\hline & Floral Visitor & Description & $\begin{array}{l}\text { Number } \\
\text { Observed }\end{array}$ & Flower & Photo ID \\
\hline 1 & & & & & \\
\hline 2 & & & & & \\
\hline 3 & & & & & \\
\hline 4 & & & & & \\
\hline 5 & & & & & \\
\hline 6 & & & & & \\
\hline 7 & & & & & \\
\hline 8 & & & & & \\
\hline 9 & & & & & \\
\hline 10 & & & & & \\
\hline 11 & & & & & \\
\hline 12 & & & & & \\
\hline 13 & & & & & \\
\hline 14 & & & & & \\
\hline 15 & & & & & \\
\hline 16 & & & & & \\
\hline 17 & & & & & \\
\hline 18 & & & & & \\
\hline 19 & & & & & \\
\hline 20 & & & & & \\
\hline
\end{tabular}

Notes (include changes in weather or any other important details): 


\section{Appendix B Volunteer Surveys}

Pollinators Count! Mid-Season Check-in Questionnaire

Your Name:

The most important reasons why I am participating in this study: please rank each of the following by placing 1 for most important through 5 for least important.

I've noticed a wide variety of pollinators around my home or garden and wanted to know more

I’ve planted specific flowers I hoped will attract pollinators

I wanted to participate in a citizen science project

I am concerned about the fate of pollinators in general

I wanted to participate in a Portland Fruit Tree Project study that fit my interests

What particular sources of information do you rely on to learn more about pollinators and pollination? Please check the appropriate box/boxes and list specific sources, if you can. Talking to others or attending presentations

Websites

Magazine articles

Books

Other media (e.g., TV, movies, You tube etc.)

I didn't know much about pollinators before I started

Please circle/highlight your responses based on how much you agree with each statement 1 (completely disagree) $\quad 5$ (neutral opinion) 10 (completely agree) I can identify more different groups/genera of bees when out in the garden: bumblebee, honey, sweat bee, carpenter bee, mason bee, etc. now, compared to before I started volunteering with Pollinators Count.
1 (disagree)
34
$5 \quad 6$
$\begin{array}{llll}7 & 8 & 9 & 10 \text { (agree) }\end{array}$

I am more interested in conserving pollinators now than before I started volunteering with Pollinators Count.
1 (disagree)
3
4
$5 \quad 6 \quad 7$
8910 (agree)

I feel it is important to collect evidence about pollinators using a scientific approach.
1 (disagree)
3
45
6
$7 \quad 8$
910 (agree)

I am more informed when it comes to pollinator-related ecology and conservation now, compared to before I started volunteering with Pollinators Count.
1 (disagree)
3
4
56
7
89
10 (agree)

I believe ecological claims about pollinators presented to me are relatively unbiased and are based on methodically collected evidence. 


$$
\begin{array}{llllllllll}
1 \text { (disagree) } & 2 & 3 & 4 & 5 & 6 & 7 & 8 & 9 & 10 \text { (agree) }
\end{array}
$$

Before I starting volunteering with Pollinators Count, as best as you can, estimate how many different kinds of bees you thought we would find in the orchards.
$1-2$
3-5
5-10
More than 10

How useful was the classroom learning session to help you learn about pollinator ecology?

$\begin{array}{llllllllll}1 \text { (not useful) } & 2 & 3 & 4 & 5 & 6 & 7 & 8 & 9 & 10 \text { (very useful) }\end{array}$

How useful was the classroom learning session to help you learn pollinator identification?

$\begin{array}{llllllllll}1 \text { (not useful) } & 2 & 3 & 4 & 5 & 6 & 7 & 8 & 9 & 10 \text { (very useful) }\end{array}$

Do you have any comments or suggestions for how the trainings could have been improved or suggestions for improvements to how information is communicated for this project.?

Please write your answer here 


\section{Polllinators Count! Post Study Questionaire}

Your Name:

Circle your answer based on how much you agree with the statement.

1 (completely disagree) $\quad 5$ (neutral opinion) 10 (completely agree)

I gained something from this project and it was worth my time.

$$
\begin{array}{lllllllll}
1 \text { (disagree) } & 2 & 3 & 4 & \begin{array}{c}
5 \text { (neutral) } \\
10 \text { (agree) }
\end{array} & 6 & 7 & 8 & 9
\end{array}
$$

I am now more likely to participate in another citizen science project

$$
\begin{array}{lllllllll}
1 \text { (disagree) } & 2 & 3 & 4 & \begin{array}{c}
5 \text { (neutral) } \\
10 \text { (agree) }
\end{array} & 6 & 7 & 8 & 9
\end{array}
$$

I feel that I made a meaningful contribution to this study and to the larger scientific community.

$$
\begin{array}{lllllllll}
1 \text { (disagree) } & 2 & 3 & 4 & \begin{array}{c}
5 \text { (neutral) } \\
10 \text { (agree) }
\end{array} & 6 & 7 & 8 & 9
\end{array}
$$

I am now more aware of the pollinators visiting flowers in my day to day life.

$$
\begin{array}{lllllllll}
1 \text { (disagree) } & 2 & 3 & 4 & \begin{array}{c}
5 \text { (neutral) } \\
10 \text { (agree) }
\end{array} & 6 & 7 & 8 & 9
\end{array}
$$

I feel more confident in my ability to identify and distinguish among major groups of bees (bumblebee, honey, sweat bee, carpenter bee, mason bee, etc.).

$$
\begin{array}{lllllllll}
1 \text { (disagree) } & 2 & 3 & 4 & \begin{array}{c}
5 \text { (neutral) } \\
10 \text { (agree) }
\end{array} & 6 & 7 & 8 & 9
\end{array}
$$

I felt adequately prepared to participate in this study following the training I received.

$$
\begin{array}{lllllllll}
1 \text { (disagree) } & 2 & 3 & 4 & \begin{array}{c}
5 \text { (neutral) } \\
10 \text { (agree) }
\end{array} & 6 & 7 & 8 & 9
\end{array}
$$

I will participate in other pollinator conservation efforts in the future (including at your own home).

$$
\begin{array}{lllllllll}
1 \text { (disagree) } & 2 & 3 & 4 & \begin{array}{c}
5 \text { (neutral) } \\
10 \text { (agree) }
\end{array} & 6 & 7 & 8 & 9
\end{array}
$$

The level of communication throughout the study was appropriate and satisfactory.

$$
\begin{array}{lllllllll}
1 \text { (disagree) } & 2 & 3 & 4 & \begin{array}{c}
5 \text { (neutral) } \\
10 \text { (agree) }
\end{array} & 6 & 7 & 8 & 9
\end{array}
$$

I would participate in this study again in the future. Please circle/highlight the best response.

$\begin{array}{lllllllll}1 \text { (disagree) } & 2 & 3 & 4 & \begin{array}{c}5 \text { (neutral) } \\ 10 \text { (agree) }\end{array} & 6 & 7 & 8 & 9\end{array}$


I believe I could have been more successful in my data collection if the following were offered (Please select all that apply)

More/better pollinator identification tools

Clearer instructions and

expectations

One-on-one, in-person guidance for Identification

pollinator biology

Other, please list:

We are interested in any other thoughts or suggestions you have to improve the training and data collection experience. Any feedback is welcome and encouraged. Please respond below.

We would like to know more about the background of those who participated in the project.

We will not share your information with anyone outside of this project.

Please indicate your total annual household income.

Less than $\$ 25,000$

$\$ 75,000-\$ 100,000$

$\$ 25,000-\$ 50,000$

$\$ 100,000-\$ 125,000$

$\$ 50,000-\$ 75,000$

$\$ 150,000$

Greater than $\$ 150,000$

Prefer not to answer

What is your age?

_Younger than 13

75 __older than 75

14-18

$19-25$

26-35

$36-50$

51-

What ethnic group do you most closely identify with?

African American

Asian

White

Native American

Hispanic/Latino

Pacific Islander Other

What is the highest level of education you have completed?

Thank you very much for participating in Pollinators Count!! 


\section{Appendix C Pollinators Count! Data}

The data gathered from this project is supplied in a .csv spreadsheet file format using UTF-8 encoding. It is in long format where each row represents a pollinator observation. Each observation includes: collector name, date, time, orchard name, sky condition (clear, partly cloudy, bright overcast, cloudy), wind condition (calm, light air, light breeze, light wind), temperature, morpho-species abbreviation, description, number observed, and plant scientific name. The file name is 'Pollinators Count Transect Observations 2017.csv'. 